\title{
Natural Products: Evidence for Neuroprotection to Be Exploited in Glaucoma
}

\author{
Annagrazia Adornetto ${ }^{1,+}{ }^{\oplus}$, Laura Rombolà ${ }^{1,+}\left(\mathbb{0}\right.$, Luigi Antonio Morrone ${ }^{1}$, Carlo Nucci ${ }^{2}$, \\ Maria Tiziana Corasaniti ${ }^{3}$, Giacinto Bagetta ${ }^{1}$ (I) and Rossella Russo ${ }^{1, *}$ \\ 1 Preclinical and Translational Pharmacology, Department of Pharmacy, Health and Nutritional Sciences, \\ University of Calabria, 87036 Rende, Italy; annagrazia.adornetto@unical.it (A.A.); \\ laura.rombola@unical.it (L.R.); luigi.morrone@unical.it (L.A.M.); giacinto.bagetta@unical.it (G.B.) \\ 2 Ophthalmology Unit, Department of Experimental Medicine, University of Rome Tor Vergata, \\ 00133 Rome, Italy; nucci@med.uniroma2.it \\ 3 School of Hospital Pharmacy, University "Magna Graecia" of Catanzaro and Department of Health Sciences, \\ University "Magna Graecia” of Catanzaro, 88100 Catanzaro, Italy; mtcorasa@unicz.it \\ * Correspondence: rossella.russo@unical.com; Tel.: +39-984-493455 \\ + These authors contributed equally to this work.
}

Received: 2 October 2020; Accepted: 14 October 2020; Published: 16 October 2020

\begin{abstract}
Glaucoma, a leading cause of irreversible blindness worldwide, is an optic neuropathy characterized by the progressive death of retinal ganglion cells (RGCs). Elevated intraocular pressure (IOP) is recognized as the main risk factor. Despite effective IOP-lowering therapies, the disease progresses in a significant number of patients. Therefore, alternative IOP-independent strategies aiming at halting or delaying RGC degeneration is the current therapeutic challenge for glaucoma management. Here, we review the literature on the neuroprotective activities, and the underlying mechanisms, of natural compounds and dietary supplements in experimental and clinical glaucoma.
\end{abstract}

Keywords: glaucoma; neuroprotection; natural products; nutrients; antioxidant; retinal ganglion cells

\section{Introduction}

Glaucoma is a heterogeneous group of optic neuropathies characterized by typical alterations of the optic nerve head $(\mathrm{ONH})$ and the progressive loss of retinal ganglion cells (RGCs) [1]. The neurodegenerative process often extends along the visual axis affecting the lateral geniculate nucleus (LGN) and visual cortex [2]. In its various subtypes (primary open angle glaucoma, POAG; primary angle closure glaucoma, PACG; normal tension glaucoma, NTG; pseudoexofoliative glaucoma, PEX; etc.), glaucoma is a leading cause of irreversible blindness with more than 112 million people expected to be affected by 2040 [3]. Age and high intraocular pressure (IOP) have been identified as main risk factors; however, NTG occurs in patients with normal IOP values and a portion of patients shows progression even if IOP is pharmacologically maintained in the physiological range [4]. Nevertheless, reducing IOP by hypotonizing drugs or surgical procedures remains the only therapeutic approach currently available [5].

The death of RGCs occurs by apoptosis, and it is the result of several mechanisms including trophic factor deprivation [6], inflammation [7], oxidative stress [8], mitochondrial dysfunction [9], excitotoxicity [10], autophagy dysregulation [11], protein misfolding [12], ischemia, and hypoxia [13]. Each of these pathways may contribute to the etiology and progression of the disease, and it is therefore a potential target for new neuroprotective, IOP-independent, therapeutic approaches. Importantly, these molecular events should not be considered as isolated but rather as a sequence of interconnected mechanisms where sustained oxidative stress acts as key factor $[7,8,14]$. Indeed, the imbalance between 
reactive species production (such as reactive oxygen species, ROS, and nitrogen reactive species, RNS), and endogenous antioxidant defenses sustain a vicious cycle that promotes chronic inflammation and creates a hostile environment for neuronal survival.

The retina is particularly susceptible to oxidative stress due to its high consumption of oxygen and proportion of polyunsaturated fatty acids, and its direct exposure to light [15]. This susceptibility increases with aging, due to the physiological decrease of antioxidant defense mechanisms [15]. Furthermore, oxidative stress can also damage the trabecular meshwork (TM) increasing its resistance to aqueous humor outflow and therefore IOP [16].

High levels of oxidative stress markers have been found in aqueous humor of patients with POAG [17] and PACG [18]. Similar results were also reported in plasma of PEX patients [19]. Furthermore, a significant correlation was reported in human TM between oxidative DNA damage, increased IOP, and visual field defects in glaucoma patients [16].

In view of the role played by oxidative stress in predisposing to glaucoma, nutrients and nutraceuticals with antioxidant, anti-inflammatory and anti-apoptotic properties have been extensively studied as a potential, neuroprotective, complementary approach to glaucoma treatment.

Here, we review the current literature on the effect of natural compounds in preclinical and clinical models of glaucoma.

\section{Vitamins}

Vitamins are organic compounds and essential micronutrients found in plants and animals (see Table 1). Vitamins A, D, E, and K are fat-soluble compounds; due to their liposolubility, these vitamins are stored in fatty tissue and liver for days or months [20]. Water-soluble vitamins, such as vitamin C and vitamins B, cannot be stored in the body and need to be replaced more often than fat-soluble ones [21]. The potential neuroprotective effect of vitamins is mainly linked to their antioxidant activity [22-25].

Table 1. Main sources of vitamins.

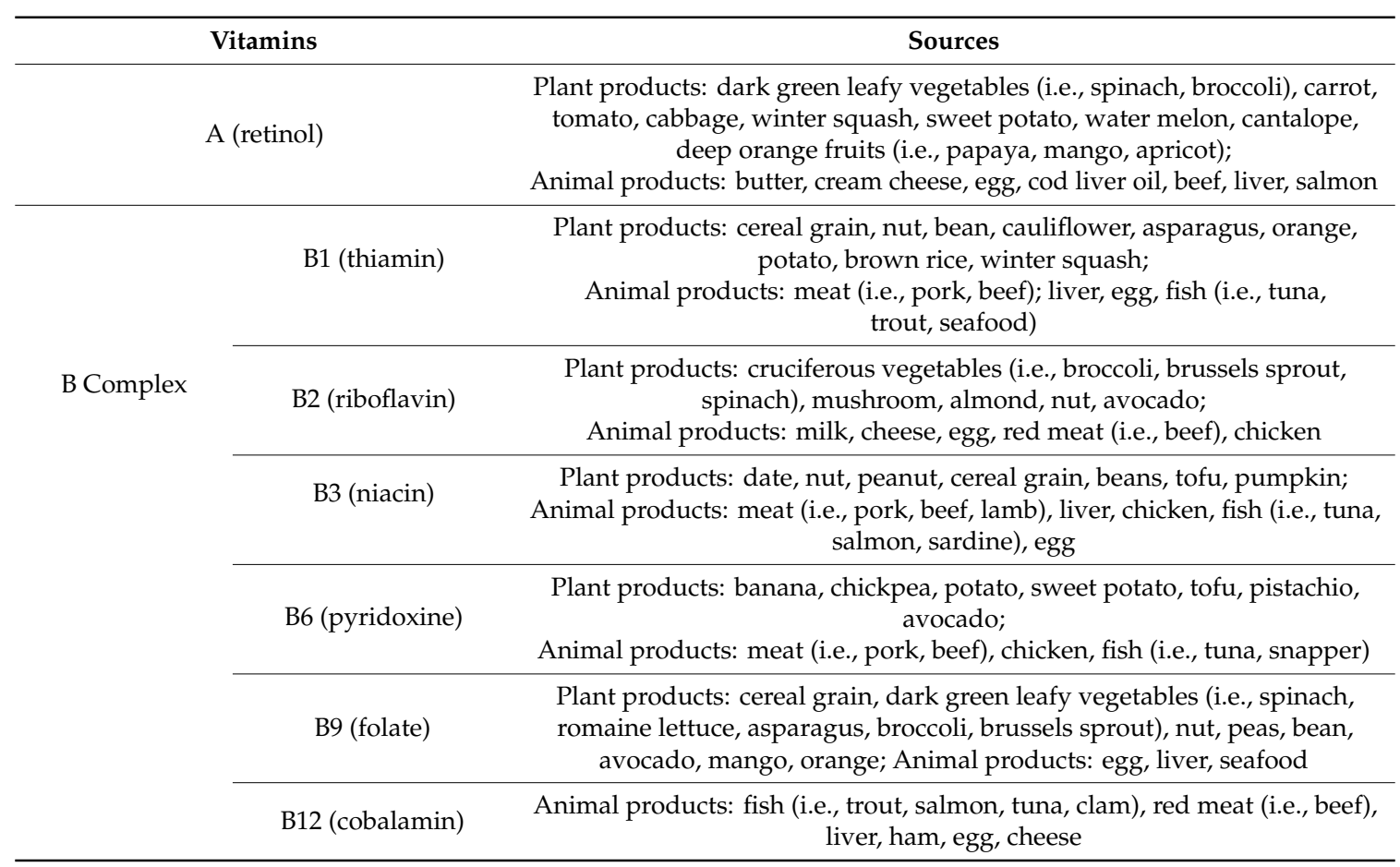


Table 1. Cont.

\begin{tabular}{cc}
\hline Vitamins & Sources \\
\hline C (L-ascorbic acid) & $\begin{array}{c}\text { Plant products: green leafy vegetables (i.e., broccoli, brussels sprout, } \\
\text { spinach), cauliflower, green and red peppers, winter squash, tomato, sweet } \\
\text { and white potatoes, many fruits (i.e., papaya, kiwi, orange, strawberries) }\end{array}$ \\
\hline D (cholecalciferol) & $\begin{array}{c}\text { Plant products: cereals, mushroom, } \\
\text { Animal products: fish (i.e., salmon, sardine, herring, mackerel), cod liver } \\
\text { oil, egg yolk, red meat, liver; } \\
\text { Sunlight exposure }\end{array}$ \\
\hline E (tocopherol) & $\begin{array}{c}\text { Plant products: nuts (especially almond), sunflower oil and seeds, soybean } \\
\text { oil, avocado, beet greens, collard greens, spinach, pumpkin, red bell pepper, } \\
\text { asparagus, mango, avocado }\end{array}$ \\
\hline
\end{tabular}

Several studies assessed the relation between vitamin-rich fruits and vegetables consumption and the risk to develop glaucoma. In the Nurse's Health Study (NHS) and the Health Professionals Follow-up Study (HPFS) on a cohort of 116,484 participants, no association was reported between dietary antioxidant intake and the risk of POAG [26]. On the contrary, in a cross-sectional study (1155 participants), a higher intake of some vegetables and fruits rich in vitamins A, B2, C, and carotenoids was associated with a decreased risk of glaucoma in old white women [27]. A cross-sectional analysis of the same cohort showed that a higher intake of green leafy vegetables and fruits rich in carotenoids and vitamins A and C was associated with a decreased odd of glaucoma in 662 old African-American women [28]. The prospective Rotterdam Study including 3502 participants aged 55 and older determined no associations between the intake of carotenoids, vitamin C, and vitamin $\mathrm{E}$ and the risk of developing glaucoma; vice versa, the group on a high intake of retinol equivalents and vitamin $\mathrm{B} 1$ had about a twofold lower risk of open angle glaucoma (OAG) as compared to the group on low intake [29]. A recent cross-sectional study on Japanese American participants, in which a total of 61 out of 581 participants were diagnosed with glaucoma, showed that a high intake of iron and low vitamin A was associated with an increased risk of glaucoma [30].

In a two-year follow up trial, the oral supplementation with vitamins A, B, C, and E, carotenoids, and antioxidant minerals with or without omega-3 polyunsaturated fatty acids (PUFAs) did not prevent visual field deterioration or thinning of the retinal nerve fiber layer in POAG patients [31]. Despite numerous studies, the association between serum vitamin levels and glaucoma prevalence in humans remains controversial. In a cross-sectional analysis (2912 participants) from the prospective National Health and Nutrition Examination Survey (NHANES), Wang and colleagues (2018) evaluated the association between supplement intake and serum levels of vitamins A, C, and E. A significant decrease in the odds of self-reported glaucoma was evident among the group currently using vitamin C supplements, but neither supplement consumption nor serum levels of vitamin A and E were related to glaucoma prevalence [32]. Accordingly, Yuki and collaborators (2010) reported lower serum levels of vitamin C in Japanese glaucoma patients with NTG as compared with controls [33]. NTG risk was not associated with vitamins B6 and B12 or folic acid serum levels [34], and in a meta-analysis study, no correlation was reported between different types of glaucoma and vitamins B6, B12, or D serum levels [34]. On the contrary, in the study by Turgut and colleagues (2010), the plasma levels of vitamin B6 were found to be increased in NTG and POAG patients while no statistical differences were observed for vitamin B12 and folate levels [35].

\subsection{Vitamin A}

Vitamin A, or retinol, is involved in many biological processes such as reproduction, immunity, cell growth, and differentiation, and it is essential for retinal function, since several metabolically active derivatives, including 11-cis-retinal and all-trans-retinoic acid, are required for vision and transcriptional gene regulation, respectively [36]. The results from studies on the association of vitamin A serum levels and glaucoma are several and controversial. Higher concentrations of vitamin A have 
been reported in patients with POAG as compared to controls [37]. On the contrary, in three other studies, no significant differences were found in vitamin A concentration between glaucomatous and normal patients $[33,38,39]$. Although the debate is still open, the results of a recent meta-analysis suggested a beneficial association of dietary intake of retinol in open angle glaucoma patients [29].

\subsection{Vitamin B Complex}

Vitamin B1, or thiamin, is an essential cofactor involved in several enzymatic reactions and in many cellular functions [40]. Optic neuropathy is a manifestation, although rare, of thiamin deficiency [41]. The Rotterdam study reported an association between low intake of thiamin and the risk of developing POAG [29]; however, a study on osteoporotic fractures did not find any correlation between vitamin B1 and POAG [27].

Vitamin B2, or riboflavin, is an essential component of two major coenzymes, flavin mononucleotide (FMN) and flavin adenine dinucleotide (FAD). These coenzymes participate in several cellular processes such as electron transport, metabolism of lipids, drugs and xenobiotics, as well as cell growth, development, and signaling [42]. The study by Coleman and colleagues (2008) observed that participants who consumed at least $2 \mathrm{mg} /$ day of vitamin B2 from natural food sources were less likely to be diagnosed with glaucoma [27].

Vitamin B3, or niacin, is the biosynthetic precursor of nicotinamide adenine dinucleotide $\left(\mathrm{NAD}^{+}\right)$ and nicotinamide adenine dinucleotide phosphate $\left(\mathrm{NADP}^{+}\right)$. NAD and NADP are required for the oxidative reaction involved in energy production, and they are substrates for enzymes involved in gene expression, signaling pathways, DNA repair, and cell death [43]. In the nervous system, vitamin B3 plays a key role in neuronal development and survival, and several findings suggest its involvement in neurological deficits and neurodegenerative diseases [43]. Retinal levels of NAD decrease with aging [44], and evidence suggest that therapies increasing NAD levels may be effective against glaucoma [45-47]. Williams and collaborators $(2017,2018)$ demonstrated that diet supplemented with nicotinamide reduced mitochondrial vulnerability and profoundly protected RGCs from degeneration in aged and DBA/2J mice $[45,48]$. In a recent study, a significantly lower concentration of nicotinamide (the amide form of vitamin B3) was reported in a cohort of POAG individuals as compared to controls [49]. In a crossover, double-masked, randomized clinical trial (57 participants with glaucoma), oral nicotinamide supplementation leads to an early improvement in inner retinal function, which is measured as photopic negative response, in glaucoma patients under IOP-lowering medications [50].

Vitamin B6, or pyridoxine, is a critical cofactor for several biochemical reactions from gluconeogenesis and glycogenolysis to amino acid and lipids biosynthesis and metabolism [51]. Vitamin B6 also plays a role in immune function and neurotransmitter biosynthesis [52]. Furthermore, vitamin B6 can quench ROS [53]. An old Russian study on patients with glaucoma and early stages of cataract reported that eye instillation of low doses of pyridoxine hydrochloride for 20 days affected vision (with changes in visual acuity and enlargement of visual field) and reduced IOP and Becker's coefficient [54]. Vitamin B6 is responsible for maintaining normal levels of homocysteine, which is an amino acid that generates oxidative stress and induces apoptosis in RGCs $[55,56]$. Higher levels of homocysteine were detected in the aqueous humor and plasma of POAG patients but not in NTG patients $[57,58]$. Nevertheless, no clinical correlation has been reported between homocysteine levels and IOP or NTG [59].

Vitamin B9, or folate, is essential for DNA and RNA synthesis; it is also involved in protein metabolism and plays a key role in breaking down homocysteine. Folate is also needed to produce healthy red blood cells and is critical during periods of rapid growth (pregnancy and fetal development) [60]. A reduction of vitamin B9 serum levels was reported in PEX patients [61].

Vitamin B12, also known as cobalamin, is one of the vitamins essential for DNA synthesis and energy production, and it is required for proper red blood cell formation and the integrity of the central and peripheral nervous system [60]. Indeed, deficiency can result in an elevation of homocysteine levels, optic neuropathy, and irreversible damage to the nervous system $[62,63]$. Türkyilmaz and 
colleagues (2013) showed that patients with vitamin B12 deficiency have a thinner retinal nerve fiber layer as compared to controls [64]. However, a study by Kang and collaborators (2014) reported no association between vitamin B12 intake and PEX [65].

\subsection{Vitamin $C$}

Vitamin C, or L-ascorbic acid, is an important physiological antioxidant; besides several other functions, it is an essential nutrient involved in tissue repair and protein metabolism [66]. An old study measured higher levels of vitamin $C$ in the aqueous humor of POAG patients as compared to controls [67], while more recent studies reported opposite results [18,68,69]. Xu and collaborators (2014) described a dose-dependent protective effect of vitamin C against oxidative insult in TM cells that was mediated by the regulation of ROS formation and ion homeostasis, and the activation of autophagy [70]. In vitro studies on TM cells from glaucomatous eyes showed that vitamin C induced the synthesis and reduced the viscosity of hyaluronic acid, increasing humor aqueous outflow through the trabeculum [71,72]. A cross-sectional study on vitamin C supplementation in a population sample in the United States found that consumption of vitamin $C$ was associated with a reduced incidence of glaucoma [39]. Interestingly, a recent study on 1763 volunteers demonstrated that O-methylascorbate, a circulating vitamin $C$ metabolite, has a significant IOP-lowering effect [73].

\subsection{Vitamin D}

Vitamin D, or cholecalciferol, is responsible for the intestinal absorption of several minerals (calcium, iron, magnesium, and zinc) [74]. In addition to calcium homeostasis and bone growth and remodeling, vitamin $\mathrm{D}$ is also involved in the regulation of cellular proliferation and differentiation, and immune response [75]. Goncavales and colleagues (2015) reported a positive correlation between vitamin D insufficiency and POAG [76]. A metabolomic analysis on plasma samples from 72 POAG patients showed alterations of vitamin D metabolic pathways as compared to 72 healthy controls [77]; furthermore, the presence of polymorphisms of vitamin $\mathrm{D}$ receptor may represent a relevant risk factor for glaucoma development [78]. These data are in agreement with the results of the cross-sectional Korean National Health and Nutrition Examination Survey study (KNHANES), in which a J-shaped association between 25-hydroxyvitamin D $(25(\mathrm{OH}) \mathrm{D})$ levels and the risk of POAG was reported [79]. More recently, a case-control study by Ayygari and coauthors (2019) highlighted that patients with advanced glaucoma had lower serum levels of vitamin $\mathrm{D}$ as compared with early glaucoma and normal subjects [80]. Accordingly, another two studies showed lower 25(OH)D serum levels in POAG patients $[78,81]$. At variance, no differences in total vitamin $\mathrm{D}$ concentration were found between patients with or without glaucoma in the retrospective cross-sectional Kangbuk Samsung health study [82].

Experimentally, topical administration of $1 \alpha, 25$-dihydroxyvitamin D (3) or its analog 2-methylene-19-nor-(20S)-1 $\alpha, 25$-dihydroxyvitamin D (3) significantly reduced IOP in non-human primates [83]. Nevertheless, no variation in IOP values was reported when vitamin $D$ was administered to healthy volunteers with low 25(OH)D levels [84].

\subsection{Vitamin E}

Vitamin E, or alpha-tocopherol, is a potent fat-soluble antioxidant that can prevent the oxidation of polyunsaturated fatty acids (PUFAs) in cell membranes. Furthermore, animal and human studies have shown that vitamin E deficiency impairs immune function [85]. In a rat model of IOP elevation, a correlation between vitamin E deficiency and increased RGCs death with higher levels of retinal lipid peroxidation has been shown [86]. Zanon-Moreno and colleagues (2013) reported lower plasma levels of vitamin E in POAG subjects [87]. Contrariwise, some studies showed an increase in vitamin E serum levels in glaucoma patients [37]. Two studies on NTG patients showed no difference in vitamin E plasma levels between patients with glaucoma and controls [33,39]; vice versa, Lopez-Riquelme and colleagues (2015) reported lower vitamin E plasma levels in NTG patients [38]. In a nonrandomized 
placebo-controlled study (30 patients), Engin and colleagues (2007) reported the neuroprotective effect of oral supplement of $\alpha$-tocopherol acetate for 12 months against glaucomatous damage [88].

\section{PUFAs}

Fatty acids (FAs) are carboxylic acids with long aliphatic chains, which constitute the building blocks of cellular lipid structures and play important functional roles as precursors of signaling molecules and energy providers [89]. Based on the number of carbon atoms and unsaturation, FAs can be distinguished in saturated fatty acids (SFAs), monounsaturated fatty acids (MUFAs), and polyunsaturated fatty acids (PUFAs). Alfa-linolenic acid (C18:3n-3) (ALA) and linoleic acid (C18:2n-6) (LA) are the precursor of omega-3 and omega-6 PUFAs, which are essential fatty acids and must be ingested with the diet [90]. LA is the most abundant PUFA in nature, and it can be found in corn, seed oils (i.e., sunflower, soybean, safflower), wheat germ, grape, and hemp; the main dietary sources of ALA are fish, flaxseeds, linseed and canola oils, salmon, tuna and herring [91]. In vivo, ALA is converted in eicosapentaenoic acid (EPA) and docosahexaenoic acid (DHA), and these can be found in seafood, in particular salmon, tuna, sardine, and mackerel and krill oils. DHA is the most important PUFA in the brain [92], and high levels of DHA are found in the retina, mainly in the discs of rods' external segments $[93,94]$.

In addition to contributing to the physical-chemical properties of cell membranes, with particular reference to the central nervous system and retina [15], PUFAs also serve as precursors of several mediators (eicosanoids, docosanoids) involved in the regulation of inflammation, immunity, blood pressure and viscosity, platelets, cellular growth, synaptic plasticity, etc. [95]. All these actions confer anti-inflammatory, antithrombotic, lipid-lowering, and vasodilating properties to omega-3 PUFAs [96-98] that can be exploited for the treatment of human pathologies characterized by a high level of inflammation, including neurodegenerative conditions [99-101].

Since a high intake of ALA promotes the production of anti-inflammatory eicosanoids, while a high intake of LA favors the synthesis of pro-inflammatory eicosanoids, the ratio between these nutrients must be balanced [91]. Relating to glaucoma, the association between the intake of omega 3, omega 6 , and their ratio, and the incidence of the disease have been evaluated in two studies, the Nurses' Health Study and Health Professionals Follow-up Study and the prospective SUN (Seguimento University of Navarra) cohort study; the results showed that participants with a high omega 3:6 ratio intake had a higher risk of developing glaucoma [102,103]. Conversely, in a cross-sectional population study (3865 participants), enhanced daily intake of EPA and DHA were linked with significantly lower risks of glaucoma. However, daily levels of total PUFAs intake in the higher quartiles were associated with a higher risk of glaucoma; this was probably due to the relative intake of omega- 3 and omega- 6 and the presence of other confounding comorbidities [32].

In view of their mechanisms of action, preclinical and clinical studies on the effect of PUFAs intake in glaucoma degeneration have either focused on its effects on IOP levels or RGC function preservation.

An increased consumption of omega-3 has been shown to decrease IOP in a rat model due to the production of prostaglandins (PGs) that possess IOP-lowering effects [104]. Interestingly, a recent clinical study showed that oral omega-3 supplementation for three months in normotensive adults significantly reduced IOP [105].

It has been suggested that a dietary combination of omega-3 and omega-6 PUFAs given for 6 months is more effective than single supplementation; in fact, a diet supplementation with a combination of EPA, DHA, and gamma linolenic acid given for 6 months prevented retinal cell structure damage and decreased glial cell activation induced by the laser-induced chronic elevation of IOP in rats [106]. A dietary deficiency in omega-3 affects retinal function with an alteration of RGCs activity, while diets rich in omega-3 help reduce the dysfunction of RGCs induced by acute IOP elevation in rats $[107,108]$. Inman and collaborators (2013) reported that the dietary administration of ALA to glaucomatous DBA/2J mice led to a significant reduction in RGCs loss and dysfunction [109]. 
Recently, it was also reported that omega-3 PUFAs supplementation potentiated the neuroprotective effect of timolol treatment in retinas of DBA/2J mice [110].

Despite the preclinical positive results on PUFA supplementation, an open-label randomized controlled trial on 117 patients with mild or moderate POAG and IOP under control with topical medications failed in reporting any benefit after oral antioxidant supplementation (mixture of vitamins and minerals) with or without omega-3 PUFAs [31].

In view of the examined literature, the role of PUFAs as a potential treatment in glaucoma remains controversial and justifies further investigation and longer-term research with a larger sample and/or with different PUFAs combinations.

\section{Palmitoylethanolamide}

Palmitoylethanolamide (PEA) is a lipid mediator synthesized during inflammation and tissue damage endowed with neuroprotective, anti-neuroinflammatory, and analgesic properties [111]. It was isolated from tissues, body fluids, and purified lipid fractions of egg yolk, soybeans, and peanut meal, and it has been found in a wide variety of food [111]. At a dosage of 600/1200 mg/d, PEA is marketed as a medical food in several European countries, and it is used as a dietary supplement in ocular diseases in Italy [112]. This lipid mediator is synthetized by the hydrolysis of the phospholipid precursor, N-palmitoyl-phosphatidyl-ethanolamine, by N-acyl-phosphatidyl-ethanolamine-selective phospholipase D (NAPE-PLD) [113], and it is degraded to palmitic acid and ethanolamine by two different hydrolytic enzymes, the fatty acid amide hydrolase (FAAH) [114] and the N-acylethanolamine-hydrolyzing acid amidase (NAAA) [115].

Its use as a dietary supplement in glaucoma was validated by different clinical data, while preclinical studies have investigated its mechanism of action highlighting an entourage effect with the endocannabinoid system [111]. This system includes the endogenous ligands $\mathrm{N}$-arachidonoylethanolamide (anandamide, AEA) and 2-arachidonoylglycerol (2-AG), which are the enzymes responsible for their synthesis and degradation, such as fatty acid amide hydrolase (FAAH) and monoacylglycerol lipase (MGL), and the cannabinoid type-1 (CB1) and type-2 (CB2) receptors [116]. AEA and 2-AG also bind to GPR55 [117], transient receptor potential vanilloid 1 (TRPV1) ion channel [111], and nuclear peroxisome proliferator-activated receptors (PPARs) $\alpha$ and $\gamma$ [118]. Early evidence indicate that the levels of PEA and 2-AG decreased significantly in eye tissues of glaucomatous patients as compared to normal donors [119], suggesting that the lipid mediators have a role in this ocular disease.

Patients with ocular disease showed protective effects after an intake of PEA as documented in clinical trials. Oral intake of PEA (600 mg/day) for fifteen days prevented the significant increase of postoperative IOP in patients who had undergone bilateral laser iridotomy as compared to those pretreated with placebo [120]. After three months of PEA oral intake, a reduction of IOP and a significantly improvement endothelial function were observed in ocular hypertension (OHT) patients as compared to placebo-treated. Interestingly, this effect lasted longer than the period of PEA administration [121]. A significant reduction of IOP values was observed in POAG and $\mathrm{OH}$ patients after oral administration of PEA for two months [122]. In NTG patients, Costagliola and colleagues (2014) demonstrated that the systemic administration of PEA for six months reduced IOP and improved visual field indices; no ocular or systemic side effects were recorded after this longer lasting treatment [123]. Recently, Rossi and colleagues (2020) demonstrated that the oral administration of PEA ( $600 \mathrm{mg} /$ day) for four months enhanced the electric activity of RGCs and retina, which was measured by pattern evoked electroretinograms (PERG), and improved IOP [124]. These clinical data, together with preclinical results, have led to speculate that PEA has at least three potential beneficial effects in patients with glaucoma [124]: (1) increase of aqueous humor outflow through the GPR55 and the PPAR $\alpha$ receptors and the involvement of the p42/44 mitogen-activated protein kinase (MAPK) pathway [112]; (2) vasorelaxation of the ophthalmic artery by acting on the transcription factors PPAR $\alpha$ [125]; and (3) engagement of the cannabinoid system, which has been shown to mediate 
neuroprotective effects in both the central nervous system [126] and eye [127]. In a rat model of ischemia reperfusion injury, AEA reduced glutamate excitotoxicity and prevented apoptosis by activating CB1 and TRPV1 receptors [128-130]. An interesting hypothesis is that PEA could compete with AEA for the FAAH active site, increasing AEA concentration and its neuroprotective effects [111].

\section{Melatonin}

Melatonin (N-acetyl-5-methoxytryptamine) is an indolamine secreted mainly by the pineal gland and known as a regulator of the circadian rhythm in mammals. Melatonin synthesis also occurs in several ocular structures, such as lachrymal glands, lens, ciliary body, and retina. The hormone exerts paracrine and autocrine effects that are either mediated by its G-protein coupled receptors, MT1 and MT2, and the putative MT3, or are receptor-independent [131]. In the eye, melatonin locally synthesized or entering from the circulation participates in the regulation of retinomotor movements, rod outer segment disc shedding, dopamine synthesis, and intraocular pressure homeostasis [132]. Moreover, due to its antioxidant and free radical scavenger properties, melatonin protects ocular tissue from oxidative stress induced by light. Indeed, melatonin is an effective antioxidant and a potent free radical scavenger acting on either ROS or RNS [133]. Moreover, its antioxidant activity is potentiated by its ability to (1) stimulate endogenous antioxidant (such as glutathione peroxidase and superoxide dismutase); (2) downregulate prooxidant enzymes; and (3) increase mitochondrial oxidative phosphorylation efficiency and reduce electron leakage (therefore reducing free radical generation). In view of its properties and also considering its lipophilic nature, which enables melatonin to easily cross the hematoencephalic and hematoretinal barriers, its ability to mitigate cell damage has been explored for several neurodegenerative diseases, including glaucoma [134].

In a rat model of chronic hypertension induced by the injection of hyaluronic acid in the anterior chamber of the eye, a subcutaneous implant of a melatonin-containing pellet reverted the alteration of retinal function and reduced RGC vulnerability; ex vivo experiments in explanted retinas demonstrated that exposure to melatonin modulated glutamatergic, GABAergic (gamma aminobutyric acid), nitrergic transmissions, and retinal redox status, suggesting that reduced excitotoxicity and antioxidant effects were involved in the neuroprotection observed in vivo [135]. Accordingly, an intravitreal injection of melatonin exerted neuroprotective and antiapoptotic effects in a rabbit model of retinal oxidative toxicity induced by glutamate [136].

In a mouse model of transient retinal ischemia, Park et al. showed that melatonin (intraperitoneally injected one hour before, at the time of ischemia, and one hour after) inhibited the increased expression of hypoxia-inducible factor- $1 \alpha(\mathrm{HIF}-1 \alpha)$, reduced Muller cells activation, and prevented RGC death [137]. The protective effects of melatonin against hypoxic damage in neonatal retina were reported by Kaur and colleagues (2013); the study showed that melatonin treatment prevented RGC apoptosis, reduced lipid peroxidation, increased retinal glutathione (GSH) content, suppressed microglial expression of pro-inflammatory cytokines (i.e., TNF- $\alpha$ and IL-1 $\beta$ ), and decreased vascular permeability [138].

Interestingly, in a model of optic nerve $(\mathrm{ON})$ transection, pinealectomy exacerbated the retrograde degeneration of RGCs while an intraperitoneal injection of melatonin protected axotomized RGCs; the exogenous administration of melatonin was effective only in pinealectomized, melatonin-deficient mice but not in non-pinealectomized animals [139], thus suggesting that the supplementation may be suitable for protection under conditions of melatonin deficiency.

In addition to its neuroprotective properties, melatonin also shows hypotensive direct effects on IOP. Oral or topical administration of melatonin reduced IOP in rabbits [140-142] and monkeys [143]. The topical administration of melatonin decreased IOP in normotensive control and glaucomatous DBA/2J mice via the MT2 receptor [144].

In human normotensive subjects, Samples et al. found that oral melatonin reduced IOP by about $10 \%$ [145]. IOP reduction was reported in patients that underwent cataract surgery when treated with melatonin [146]. More recently, a short-term prospective study showed a reduction of IOP value in normotensive subjects taking a melatonin-based supplement [147]. However, the study lacked 
a placebo group, and the reported IOP reduction was only limited to $1 \mathrm{mmHg}$. Pescosolido and colleagues (2015), in a pilot study on 10 POAG patients treated with multiple hypotensive topical drugs, reported that oral treatment with agomelatine, a melatonin analogue, was able to significantly further reduce IOP [148].

Interestingly, mice lacking the MT1 receptor have elevated IOP at night and a reduced number of RGCs [149,150], and melatonin blood levels are altered in patients with glaucoma [151], suggesting that dysfunctional melatonin signaling may represent a possible risk factor for glaucoma.

\section{Citicoline}

Citicoline (cytidine-5'-diphosphocholine, CDP-choline) is a naturally occurring endogenous compound acting as a choline donor. Indeed, after oral administration, citicoline bioavailability is higher than $90 \%$, and it is fast metabolized to cytidine and choline [152]. Citicoline functions as an intermediate in the biosynthesis of cell membrane phospholipids and as a precursor of the neurotransmitter acetylcholine [153]. As a dietary supplement, citicoline has been used as a neuroprotective agent in several neurological disorders, including Parkinson's and Alzheimer's diseases, dementia, stroke, and glaucoma [154-157]. The neuroprotective effects of citicoline are mediated by several mechanisms such as the maintenance of sphingomyelin and cardiolipin levels (a component of the inner mitochondrial membrane essential for mitochondrial electron transport), restoration of phosphatidylcholine levels, increased activity of glutathione synthesis, reduction of lipid peroxidation, and attenuation of free fatty acid release [158]. Furthermore, citicoline increases acetylcholine, dopamine, noradrenaline, and serotonin levels in several brain regions $[159,160]$ and dopamine release in retina [161].

The neuroprotective properties of citicoline have been shown in several paradigms of experimental glaucoma. In a mouse retinal explant, citicoline exerted antiapoptotic effects on damaged RGCs (by reducing caspase-9 and caspase-3 activity) and supported axon regeneration [162]. After partial ON crush, intraperitoneal treatment with citicoline protected RGCs and their axons from delayed neurodegeneration and increased retinal expression of the antiapoptotic protein Bcl-2 [163]. In rat primary retinal cultures exposed to glutamate or high glucose, citicoline exerted antiapoptotic effects and reduced synaptic loss [164]. Following an intravitreal injection of kainic acid in rat, intraperitoneal injection of citicoline prevented changes of retinal thickness and attenuated the upregulation of nitric oxide synthase (NOS) isoforms [165]. In the same animal model, Park and colleagues $(2006,2007)$ reported a reduction of extracellular signal-regulated kinase 1/2 (ERK1/2) activation and clusterin expression [166,167].

The clinical efficacy of citicoline treatment in glaucoma patients has been proven by several trials. Intramuscular or oral administration of citicoline for two 60-day periods has been associated with an improvement of retinal function (evaluated by pattern electroretinogram recording, PERG) and neural conduction along the visual pathway (evaluated by visual evoked potential recordings, VEP) in glaucoma patients with moderate visual field defects [168]. An extension of citicoline treatment up to 8 years prevented the regression observed after 120 days from treatment suspension and stabilized the improvement of VEP and PERG parameters [169]. The study by Ottobelli and colleagues (2015) confirmed the long-term beneficial effect of oral supplementation with citicoline, suggesting that the treatment might significantly slow down the progression rate of glaucoma [170]. Furthermore, topical treatment with citicoline eyedrops in open angle glaucoma patients was effective in enhancing PERG amplitude and improving VEP parameters [171]. Last, the results of a pilot randomized placebo-controlled clinical trial on 80 patients with mild to moderate OAG (primary or PEX) receiving citicoline eyedrops or placebo for 3 years suggest that citicoline might reduce disease progression in patients with IOP $<18 \mathrm{mmHg}$ [172]. 


\section{Coenzyme Q10}

Coenzyme Q10 (CoQ10), or ubiquinone, is an important cofactor of the mitochondrial electron transport chain and a potent lipid-soluble antioxidant [173]. CoQ10 acts by maintaining the mitochondrial membrane potential, sustaining ATP synthesis, and preventing ROS generation $[174,175]$. Several in vitro and in vivo studies support the neuroprotective effect of CoQ10 in retinal diseases [176]. In a rat model of transient IOP elevation, the topical administration of CoQ10 decreased extracellular glutamate levels, minimized retinal damage, and prevented apoptotic cell death $[177,178]$. The antiapoptotic effects of CoQ10 may involve the inhibition of the mitochondrial permeability transition pore (MPTP) opening that prompts the apoptosis intrinsic execution pathway [179]. Ju and colleagues (2018) tested the effect of a diet supplement with ubiquinol (the reduced form of CoQ10) in a mouse model of retinal ischemia/reperfusion injury; the treatment prevented apoptotic cell death and enhanced RGC survival by modulating the Bax/Bad/Bcl-xL pathway [180]. Diet supplementation with CoQ10 for 6 months significantly promoted RGC survival and preserved RGC axons in the lamina cribosa in glaucomatous DBA/2J mice; CoQ10 treatment, as compared to a control diet, reduced the upregulation of NMDA receptor subunit type 1 (NR1), NMDA receptor subunit type 2A (NR2A), SOD2, and heme oxygenase-1 (HO-1) protein expression and prevented alteration of the mtDNA content [181]. Interestingly, an in vitro study testing the effects of $\mathrm{H}_{2} \mathrm{O}_{2}$-induced oxidative stress in $\mathrm{ONH}$ astrocytes demonstrated that $\mathrm{CoQ} 10$ treatment triggered mitochondrial biogenesis and preserved mitochondrial morphology and mass while maintaining oxidative phosphorylation system (OXPHOS) protein expression and cellular ATP production [182].

Due to the large molecular weight and hydrophobicity, topical CoQ10 has a poor intraocular penetration and bioavailability [183]. Furthermore, this compound is a substrate of the P-glycoprotein (P-gp), which is an efflux membrane transporter expressed on corneal epithelial cells and RGCs [184]. For these reasons, CoQ10 is usually used in combination with vitamin E, which ameliorates the bioavailability of CoQ10 by inhibiting P-gp [185]. Davis and collaborators (2017) observed that the formulation of CoQ10 into micelles using the vitamin E derivative D- $\alpha$-tocopherol polyethylene glycol 1000 succinate (TPSG) were neuroprotective in primary mixed retinal cultures exposed to mitochondrial damage [184]. An in vivo topical application of CoQ10 micelles prevented RGC apoptosis in a rat model of ocular hypertension (OHT) and following mechanic ON $[184,186]$.

In a randomized clinical study on $64 \mathrm{PEX}$ patients treated with a topical combination of vitamin $\mathrm{E}$ and CoQ10 (CoQun $\left.{ }^{\circledR}\right)$, a reduction of oxidative stress, measured by decreased levels of SOD in the aqueous humor, was reported [187]. In a pilot study enrolling 43 OAG patients in monotherapy with $\beta$-blockers, Parisi and collaborators (2014) reported a beneficial effect on the inner retinal function, with consequent enhancement of the visual cortical responses, in patients treated with CoQun ${ }^{\circledR}$ drops (instilled twice daily) for 6 or 12 months [188]. Currently, a multicenter controlled clinical trial on 612 POAG patients has been designed to evaluate the efficacy of topical combination of vitamin $\mathrm{E}$ and CoQ10 (CoQun $\left.{ }^{\circledR}\right)$ [189].

\section{Taurine}

Taurine (2-aminoethylsuphonic acid), a sulfur amino acid synthesized in the liver of most mammals, is present in high levels in tissues such as muscles and eyes (mainly in the retina), and it is mostly obtained from diet (e.g., meats, seafood and fish) [190]. Intake of the amino acid from dietary sources is highly dependent on taurine transporter expression [191]. In retinal cells, taurine uptake was demonstrated in retinal pigment epithelium, retinal glial cells, RGCs, and cell photoreceptors [192]. Nutritional taurine depletion has been shown to cause photoreceptor degeneration in cats [193], monkeys [194] and dogs [195], suggesting that taurine endogenous synthesis can be insufficient. Using a metabolomic approach, low levels of taurine were measured in patients with POAG as compared with age- and sex-matched non-POAG controls. The crucial role of taurine in retinal protection was evident in epileptic patients treated with vigabatrin, showing that retinal phototoxicity correlated with 
insufficient taurine plasma levels [196]. Retinal degenerative effects were observed in rats treated with taurine transport inhibitors, such as $\beta$-alanine or guanidoethane sulfonate (GES) [197,198].

It has been suggested that taurine supplementation may have a neuroprotective effect in retina [199]. Accordingly, taurine improved RGC survival in a rat retinal explant exposed to serum deprivation or N-methyl-D-aspartate (NMDA) [200]. The same authors observed the protective effects of taurine intake in DBA/2J mice and rats with episcleral vein occlusion and in a model of retinitis pigmentosa with secondary RGC degeneration [200]. Furthermore, the antiapoptotic effect of taurine was recently reported against NMDA-induced retinal excitotoxicity in rats [201-203].

Although the mechanism underlying the protective effect of taurine on RGCs is not completely clarified, it was suggested that it inhibits NADPH oxidases, which are the primary source of superoxide induced by NMDA receptor activation [204]. Successively, it was demonstrated that the selective blockade of taurine transporter prevented the taurine-mediated increase of RGC survival, suggesting that the neuroprotective effects of taurine are mediated by its intracellular/mitochondrial action [205].

Taurine is structurally related to the neurotransmitter gamma aminobutyric acid (GABA); therefore, it has been suggested that its neuroprotective effects could be mediated by the interaction with GABA receptors [190]. Indeed, GABA-B receptors antagonist prevented the taurine-elicited neuroprotective effect in RGCs [205].

\section{Flavonoids}

Flavonoids are secondary metabolites of plants, which are generally categorized as phenols or polyphenols. The classification of flavonoids is based on the level of oxidation in the ring structure; however, major dietary flavonoids are often classified under six groups (i.e., anthocyanidins, flavonols, flavanols, isoflavonoids, flavones, and flavonones) [206].

Over 4000 flavonoids have been identified. High concentrations of flavonoids are present in fruits and vegetables but also in red wine and chocolate [207]. These compounds have been shown to exert antioxidant and anti-inflammatory effects in different pathological states, including cancer, cardiovascular diseases, and neurodegenerative disorders [208]. Clinical data analyzed in systematic reviews suggest that flavonoid intake can help in maintaining or restoring the visual field in patients with OHT or glaucoma, although no significant effects were observed on IOP values [209,210]. In particular, the main effects were reported with anthocyanins, Ginkgo biloba, and green tea.

\subsection{Ginkgo Biloba Extract (GBE)}

Ginkgo Biloba extract (GBE) is obtained from the leaves of Ginkgo Biloba, which is an ancient Chinese tree. The extract contains several chemical constituents, including "flavones glycosides", such as quercetin, kaempherol, and isorhamnetin, and "terpene lactones", such as ginkgolides A, B, $\mathrm{C}$, and bilobalide. Many types of GBEs are found on the market, but clinical and preclinical studies have been performed mainly using the standardized EGb 761 containing flavonoids (24\%), terpene lactones $(6 \%)$, and a low concentration of ginkgolic acids $(0.0005 \%)$, which is known to cause allergenic and genotoxic effects. EGb761 is used for ailments associated with aging, such as neurodegenerative disorders, cognitive decline, vascular insufficiency [211], and glaucoma [212].

Neuroprotective effects of Ginkgo biloba were observed in different animal models of glaucoma [212]. In the episcleral vein cauterization model, treatment with EGb 761 for 5 months induced a significant reduction of RGC loss [213]. Similar results were observed in a model of ON crush following four weeks of treatment with the extract [214-216].

Clinical studies on GBE were based on two different outcomes, blood flow or visual field improvement [212]. Park et al. (2011) observed an increase of peripapillary blood flow in patients with NTG after 4 weeks of GBE ( $80 \mathrm{mg}$ twice daily) oral administration [217]. The effects of GBE on ocular blood flow were confirmed in patients with OAG treated for four weeks with a rich antioxidant dietary supplement containing $120 \mathrm{mg} /$ day of GBE [218]. Supplementation with GBE (40 $\mathrm{mg}$ three times daily) for 4 weeks induced a statistically significant improvement in visual field indices and 
pre-existing progressive visual field deficits in Italian patients with NTG when compared with placebo; no differences in IOP or blood pressure were reported [219]. Positive results were observed also by Shim and colleagues (2012) that measured an improvement of the visual function in individuals with NTG after oral intake of Bilberry anthocyanins and GBE [220]. However, a different study in Chinese patients with NTG treated with the same posological scheme of GBE reported no significant improvements in visual field defects [221]. A possible explanation for these contrasting results may reside in the variation of study population and racial differences [212].

\subsection{Green Tea}

Tea beverage, made from the infusion of the leaves of Camellia sinensis, contains polyphenols, i.e., flavanols (also known as catechins), alkaloids (such as caffeine and theobromine), carbohydrates, tannins, and minerals (such as fluoride and aluminum). The catechins present in green tea are (-)-epigallocatechin-3-gallate (EGCG), (-)-epigallocatechin (EGC), (-)-epicatechin-3-gallate (ECG), and (-)-epicatechin (EC). Other food rich in catechins are red wine, dark chocolate, legumes, and nuts. EGCG is the major catechin and has been used for most of the research carried out to investigate the health effects of catechins [222]. A clinical study showed that in OAG patients with early to moderate ON damage, oral treatment with EGCG (200 mg/day) induced a small but significant effect on inner retinal function evaluated by pattern evoked electroretinograms (PERG) [223]. A significant increase in the a- and b-wave amplitudes of the electroretinogram (ERG), other than a decrease of the apoptotic pathway, was observed in an in vivo preclinical study using a retinal ischemia/reperfusion model [224]. Neuroprotective effects on RGCs were shown in the ON crush model after pre and post systemic treatment with EGCG [225]. The neuroprotective effects of catechin (50 mg/kg, intraperitoneal (i.p.)) reported by Peng and colleagues $(2008,2010)$ in ischemia/reperfusion (I/R) and optic nerve axotomy models were associated with a decrease of nitric oxide expression and upregulation of the Akt/PI3kinase pro-survival pathway [226,227].

The protective effects of green tea extract (GTE) in toto was recently investigated. Pharmacokinetic studies, performed in rats, indicated that after oral intake of GTE, catechins (e.g., EGCG, EGC, and EC) are quickly distributed into various eye compartments and exert pro- and antioxidative effects depending on the tissues and EGCG concentration [228]. Yang et al. (2019) demonstrated that an intragastric administration of GTE, 4 times/day with a dose of $275 \mathrm{mg} / \mathrm{kg}$, ameliorated ischemia-induced RGC degeneration and prevented RGC function impairment through antiapoptotic, antioxidant, and anti-inflammatory effects [229].

\section{Resveratrol}

Resveratrol (3,5, $4^{\prime}$-trihydroxystilbene) is a polyphenol, first isolated from the roots of white hellebore (Veratrum grandiflorum O. Loes) and Polygonum cuspidatum. It is found in vegetables and fruits, including berries, grapes, and peanuts, and in red wine. It has been shown that resveratrol can slow down the progression of a wide variety of illnesses, including cancer, cardiovascular, neurodegenerative disease, and ocular diseases [230].

Several preclinical studies investigated the health benefits of this polyphenol in different glaucoma models. Oral resveratrol administration ( $250 \mathrm{mg} / \mathrm{kg} /$ day for four weeks) reduced RGC loss and preserved pupillary light response following ON crush injury [231]. The same authors by using mice with conditional deletion of sirtuin-1 (SIRT-1) in neurons demonstrated the involvement of SIRT-1 activation in the resveratrol-mediated RGC neuroprotection [231]. Dietary supplementation for 11 months with a low dose of resveratrol $(31 \mathrm{mg} / \mathrm{kg} /$ day) afforded neuroprotection in RGC injury induced by $\mathrm{ON}$ nerve crush, increasing the expression of the cytoplasmic binding immunoglobulin protein (BiP), nuclear C/EBP homologous protein (CHOP), and nuclear X-box binding protein-1 (XBP-1) [232]. In a model of chronic OHT, Zhang et al. (2018) observed that the intragastric administration of resveratrol $(20 \mathrm{mg} / \mathrm{kg} / \mathrm{d}$ ) for 4 weeks prevented retinal damage and RGC apoptosis by activation of the AMP 
activated protein kinase/peroxisome proliferator-activated receptor-c coactivator- $1 \alpha$ (AMPK/PGC- $1 \alpha$ ) signaling pathway and upregulation of mitochondrial proteins [233].

In the ischemia/reperfusion model, intraperitoneal (i.p.) administration of resveratrol reduced the decrease of retinal thickness and preserved cellular density in ganglion cell layer (GCL) via the downregulation of caspase- 3 and caspase- 8 expression and suppression of gliosis-related inflammation [234,235]. Recently, Cao and colleagues (2020) observed that the intravitreal administration of resveratrol $(300 \mu \mathrm{M})$ delayed RGC apoptosis in a model of transient IOP elevation. The reported neuroprotection was associated with a decreased generation of ROS and expression of acetyl-p53, and an upregulation of brain-derived neurotrophic factor (BDNF) and its tyrosine receptor kinase B (TrkB) receptor [236]. These preclinical data suggest that resveratrol induces protective effects by modulating oxidative stress as well as apoptotic and inflammatory pathways. This hypothesis is supported by in vitro experiments in retinal cell lines. Photoreceptor death induced by glucose deprivation (GD) was inhibited by the polyphenol through the inhibition of caspase- 9 and caspase-3 and elevation of SIRT-1 expression and activity [237]. In glaucomatous human TM, treatment with resveratrol prevented the increase of IL- $1 \alpha$, IL-6, IL-8, ROS, and endothelial-leukocyte adhesion molecule 1 (ELAM- 1 ) and reduced the expression of the senescence markers sa- $\beta$-gal, lipofuscin, and the accumulation of carbonylated proteins $[238,239]$. Anti-inflammatory effects of resveratrol were confirmed in cultured ONH astrocytes where the treatment reduced iNOS [239] and decreased $\mathrm{PGE}_{2}$ receptor expression [240].

\section{Forskolin}

Forskolin is a diterpene (7beta-acetoxy- 8,13-epoxy-1alpha,6beta,9alpha-trihydroxy-labd-14-en -11-one) extracted from the roots of Coleus Forskohlii (Lamiaceae). The cellular effects of forskolin rely on its ability to activate the catalytic subunit of adenylate cyclase, increasing the intracellular levels of cAMP [241].

Forskolin has been shown to be effective in lowering IOP in rabbits, monkeys [242-244], and humans [242-246]. In an open label pilot study enrolling 16 POAG patients, supplementation with forskolin, rutin, and vitamins B1 and B2 potentiated the hypotonizing effects of pharmacological treatments [247]. Similarly, in a randomized controlled trial (97 subjects), oral administration of forskolin and rutin was associated with a better control and a further reduction of IOP in POAG patients poorly responsive to multitherapy treatment [248].

More recently, Mutolo and colleagues (2016) reported a reduction of IOP values and an improvement of PERG amplitude in POAG patients under IOP-lowering medications and treated with a combination of forskolin, homotaurine, carnosine, and folic acid [249].

In vitro and in vivo evidence suggested that forskolin protects RGCs against glaucoma-related insult. Some of these neuroprotective effects seem to be mediated by the activation and potentiation of neurotrophins' activity $[250,251]$. Indeed, the addition of forskolin to brain-derived neurotrophic factor (BDNF), ciliary derived neurotrophic factor (CTNF), and insulin-like growth factor-1 (IGF-1) in culture medium promoted RGC survival [251,252]. Similarly, when added to a combined treatment with BDNF and CTNF, forskolin significantly improved the survival of axotomized RGCs in cat retina $[250,253]$. Forskolin partially prevented RGC death in a rat model of retinal ischemia/reperfusion injury, and this effect was potentiated by the simultaneous administration of homotaurine and L-carnosine [254]. The observed neuroprotection was associated with reduced calpain activity and upregulation of the phosphoinositide-3-kinase/protein kinase B (PI3K/Akt) pathway, while it was insensitive to protein kinase A (PKA) inhibition and independent from the hypotensive action of forskolin [254]. More recently, the protective efficacy of a dietary supplement containing forskolin, homotaurine, spearmint, and vitamins B was reported in a mouse model of ON injury, and following a transient increase of IOP, the supplement intake reduced RGC loss, preserved ERG photopic negative response, and reduced pro-apoptotic markers and inflammatory cytokines expression $[255,256]$. 


\section{Curcumin}

Curcumin is a polyphenolic orange and water-insoluble pigment isolated from turmeric, the rhizome of Curcuma longa L., belonging to the Zingiberaceae family. This spice has been widely used as food flavoring and coloring agent and, in Asian countries, as herbal medicine [257].

Curcumin has been reported to attenuate cognitive deficits, neuroinflammation, and plaque pathology in Alzheimer's disease models [258], and it showed neuroprotection in cerebral ischemia [259] and in neuronal cultures exposed to excitotoxic stimuli [260].

Several pharmacological properties have been attributed to curcumin including antimicrobial, anti-inflammatory, antioxidant, antimutagenic, and anticancer activities [261,262]. Indeed, it has been shown that curcumin effectively inhibits lipid peroxidation and ROS, decreases inflammatory cytokines, reduces oxidative stress, and increases antioxidant enzymes in age-related eye disease [263,264].

The mechanisms by which curcumin induces its effects are yet to be fully elucidated; however, it can modulate the expression and activation of proteins involved in the inflammatory response (i.e., chemokines, interleukins, and transcription factors). Curcumin attenuates mitochondrial-mediated oxidative stress [265], downregulates cyclooxygenase-2 (COX2) and inducible nitric oxide synthase (iNOS), reduces astrogliosis by downregulating the janus kinase 2 (JAK2)- signal transducer and activator of transcription 3 (STAT3) pathway [266] and possesses antiangiogenic activity via modulation of the vascular endothelial growth factor (VEGF)/VEGF receptor (VEGFR)/K-Ras pathway [267]. Several studies identified nuclear factor- kB (NF-kB) as one of the mediators for curcumin's effects [268,269], while others suggest that curcumin may exert anti-inflammatory effects through the activation of peroxisome proliferator-activated receptor-gamma (PPAR- $\gamma$ ) [270]. A recent meta-analysis of randomized controlled trials showed that curcumin improves systemic markers of oxidative stress and increases the serum activities of antioxidant enzymes such as SOD, catalase, and glutathione peroxidase [271].

It has been shown that the antioxidant and anti-inflammatory properties of curcumin may protect RGCs from glaucoma-related stimuli. Curcumin prevented NMDA-induced apoptosis in mixed rat retinal cultures [272]. Interestingly, curcumin-mediated neuroprotection against excitotoxicity was correlated with an increased level of the NMDA receptor subunit type 2A (NR2A) and decreased amplitude of NMDA currents [273].

Supplementation of rodent diet with $0.01 \%$ to $0.25 \%$ curcumin protected RGCs and microvessels from the damage induced by ischemia/reperfusion insult through its inhibitory effects on NF-kB and STAT3 activation and monocyte chemoattractant protein-1 (MCP-1) upregulation [274].

In a rodent model of OHT induced by episcleral veins cauterization, intragastric administration of curcumin (10 mg/kg/day) for 6 weeks significantly inhibited the death of RGCs [275]. However, the dosage reported in these experimental models is equal to $800 \mathrm{mg} /$ day in humans, which has been associated to side effects such as nausea, diarrhea, and the upregulation of lactate dehydrogenase and alkaline phosphates serum levels [276]. The systemic therapeutic treatment with curcumin is further challenged by its limited oral absorption and systemic availability [277]; furthermore, the extremely low water solubility would represent an obstacle for topical administration in ophthalmic diseases. To overcome these limitations, Davis and colleagues [261] developed a novel nanocarrier formulation of curcumin in D- $\alpha$-tocopheryl polyethylene glycol succinate (TPGS)/Pluronic F127 that significantly increased curcumin solubility $(4.3 \mathrm{mg} / \mathrm{mL})$. This formulation was found to be neuroprotective in R28 retinal cultures exposed to glutamate or cobalt chloride (hypoxia mimetic), and given topically twice daily for three weeks (starting two days prior induction of the insult), it significantly preserved RGC density in a rat model of OHT and following partial ON transection [261]. Pursuing the aim to overcome the pharmacokinetic limitations of curcuma, increase its penetration into aqueous humor, and guarantee a sustained and prolonged release, while reducing systemic toxicity, a more recent study developed a thermosensitive hydrogel containing latanoprost and curcumin-loaded nanoparticles for topical eyedrop formulation (application) [278]. Treatment with the hydrogel of human TM cells exposed to $\mathrm{H}_{2} \mathrm{O}_{2}$ prevented the cellular damage induced by oxidative stress via decreasing 
inflammation-related gene expression (TNF- $\alpha, \mathrm{IL}-1 \alpha)$, mitochondrial ROS production, and caspase-3 activity [278]. Accordingly, a previous study showed that the antiapoptotic effect of curcumin in TM cells exposed to oxidative stress was mediated by the inhibition of pro-inflammatory factors (i.e., IL-6, ELAM-1, IL-1alfa, and IL-8), reduction of carbonylated protein levels, and decrease of the senescence marker SA- $\beta$-gal activity [279].

\section{Lycium barbarum}

Lycium barbarum L. is a Solanaceous defoliated shrub widely distributed in northwestern China; the plant also grows in southwestern Europe and Mediterranean areas. The Lycium barbarum's fruit, called wolfberry or goji berry, has long been known in China and other Asian countries as traditional herbal medicinal and food supplement; more recently, it has becoming very popular in Western countries. Health claims for Lycium barbarum are anti-aging effects, balance of the immune system, improvement of lung, kidney, and liver function, and preservation of vision [280-282]. The fruits of Lycium barbarum contain several bioactive compounds including abundant polysaccharides (LBP), polyphenols/flavonoids, carotenoids (zeaxanthin and $\beta$-carotene), amino acids, vitamins (in particular riboflavin, thiamin and ascorbic acid), fatty acids, and trace of zinc, iron, and copper. The most active component of the fruit has been identified in the polysaccharide components [283]. LBP (i.e., water-soluble conjugates including rhamnose, xylose, glucose, mannose, arabinoside, and galactose) accounts for $5-8 \%$ of dried fruit and about $40-45 \%$ of water fraction; it is endowed with a wide array of pharmacological activities (or is responsible for most of the health benefits mediated by the berry) including anti-aging, cytoprotective, antioxidant, anti-inflammatory, and immunomodulatory properties [281,284,285].

Lycium barbarum has been shown to afford neuroprotection to RGCs in animal models of chronic and acute OHT without affecting IOP values. Mi and colleagues (2012) showed that in mice subjected to acute OHT, oral pretreatment with LBP improved the survival ratio of RGCs, reduced the thinning of retinal inner nuclear layers, and preserved the integrity of the blood-retinal-barrier (BRB). The prevention of vascular damage and the neuroprotection observed were ascribed to the downregulation of receptor for advanced glycation end products (RAGE) and their ligands (AGE), endothelin-1 (ET-1), amyloid $\beta$-peptide $(A \beta)$, and the related signaling pathways [286]. In addition, He and colleagues (2014) suggested that the activation of the erythroid 2-related factor (Nrf2)/heme oxygenase-1 (HO-1) antioxidant pathway contributes to the protection afforded by LBP following acute OHT [287].

Chan and coauthors (2007) first demonstrated that oral administration of the aqueous extract of dried fruit of Lycium barbarum protects RGCs in an in vivo model of chronic OHT induced by argon laser photocoagulation; the dose-response showed a U-shaped curve with the maximum protection obtained at $1 \mathrm{mg} / \mathrm{kg} /$ die given for 21 days [288]. The same research group suggested that the observed neuroprotection was associated with the modulation of microglia activation in the inner retina [289] and might involve the direct upregulation of neuronal crystallins, especially $\beta$ B2-crystallin [290].

While the previous studies demonstrated the benefits of LBP applied before the OH induction (pretreatment), Lakshmanan and colleagues (2019) recently assessed the effects of the treatment when this was applied after the induction of chronic OHT (post-treatment). LBP post-treatment preserved RGC density and function. Pre and post-treatment intervention with LBP prevented RGC loss and preserved retinal structure and function, although pretreatment offered superior neuroprotection [291].

The neuroprotective effects of LBP have also been reported in IOP-independent glaucoma models. In rats that had undergone partial optic nerve transection (PONT) feeding with LBP, for 7 days before the insult, there was delayed secondary RGC degeneration and improved retinal function by inhibiting oxidative stress, increasing the JNK/c-jun pathway and modulating the activation of microglia/macrophages in the retina [292,293]. More recently, the neuroprotection afforded by LBP in the PONT model has been associated with the increase of macrophage M2 polarization and the reduction of the autophagy marker LC3II [294]. 
While LBP seems promising in preclinical animal studies, its effects on patients with ocular pathologies remain unknown. However, a recent double-masked clinical trial in retinitis pigmentosa patients showed that a daily supplementation with Lycium barbarum for 12 months preserved macular thickness and visual acuity and, therefore, supported the data reported in preclinical studies regarding the potential retinal neuroprotective effect of Lycium barbarum [295].

\section{Saffron}

Saffron is the dried red stigmas of Crocus sativa L. flower, which is a perennial stemless herb belonging to the Iridaceae family. Saffron is widely used in food preparation as a coloring and flavoring spice, and it is also long been used in traditional medical practice for its anticatarrhal, expectorant, eupeptic, anti-spasmodic, emmenagogue, and nerve-sedative properties [296].

Saffron stigmas contain more than 150 volatile and non-volatile active compounds [297]; safranal is the main component of the volatile fraction, while non-volatile constituents comprise crocins, crocetin, picrocrocin, and flavonoids (quercetin and kaempferol); see [298]. Crocin and crocetin (an aglycone of crocin) are potent antioxidants; however, their protective activities may rely on more complex mechanisms involving the modulation of gene expression. Nam et al. (2010) showed that crocin inhibits NF-kB activation and suppresses the production of nitric oxide (NO), TNF- $\alpha$, IL- $\beta$, and ROS from activated microglial cells $[299,300]$. Several studies reported the beneficial effects of saffron extract or its components in in vivo and in vitro models of retinal degeneration. Protective effects of orally administered crocetin were reported in mice subjected to retinal ischemia, and these were mediated by the reduction of mitogen-activated protein kinases activation (p38, JNK) and redox-sensitive transcription factors (i.e., c-Jun and NF-kB) [301]. Oral administration of crocetin significantly protected against light-induced retinal damage [302], reduced retinal edema in a mouse model of retinal vein occlusion [303], and prevented inner retinal damage induced by an intravitreal injection of NMDA in mice via inhibition of the caspase pathway (preventing the activation of caspase-3 and caspase-9) [304].

Crocin analogs were found to raise blood flow in the retina and choroid of rabbits subjected to acute IOP, thus improving oxygenation and nutrient supply and facilitating retinal function recovery [305]. An intraperitoneal injection of crocin significantly enhanced RGC survival in a rat model of retinal ischemia/reperfusion injury through the activation of the PI3K/Akt signaling pathway [306]. In the same model of retinal damage, prevention of RGC death by crocin (given intraperitoneally) was associated with the upregulation of antioxidant enzymes (i.e., GSH and SOD), reduction of ROS and malondialdehyde (MDA) levels, and decreased phosphor-extracellular signal-related kinase (p-ERK) expression [307].

A recent study showed that oral administration of a hydrophilic saffron extract standardized to $3 \%$ crocin prevented RGC death and repressed retinal microglial activation in a mouse model of laser-induced OHT [308].

Despite the preclinical data, the clinical significance of saffron or its components in glaucoma patients is yet to be proven, and only a pilot clinical study has been published showing that oral saffron supplementation exerts a significant hypotensive effect in patients with primary open angle glaucoma [309].

\section{Erigeron breviscapus}

Erigeron breviscapus (vant.) Hand.Mazz. (EBHM) is a medicinal plant endemic in southwestern China. EBHM has been used to treat heart disease, cerebral infarction, digestive disorders, and apoplexy [310]. The major active components are scutellarin, a flavone glucuronide (5,6,4'-trihydroxyflavone-7-O-glucuronide), 3,5-dicaffeoylquinic acid, and erigoster B [311]. It has been shown that EBHM is endowed with neuroprotective effects. EBHM extract prevented neuronal apoptosis induced by transient focal ischemia [312], and scutellarin alleviated motor deficits caused by multiple sclerosis by inhibiting the apoptosis of neural stem cells and promoting their differentiation 
into myelin-producing oligodendrocytes [313]. Recently, the neuroprotective effects of EBHM have been investigated in experimental models of retinal degeneration. It has been shown that EBHM improved the ON axoplasmatic transport altered by acute IOP elevation [314] and prevented RGC death induced by ON crush in rats [315]. Visual function improvement by restoring multifocal electroretinogram (mfERG) altered by elevated IOP in rats was reported following treatment with EBHM [316].

Zhu and colleagues (2018) demonstrated that EBHM extract increased the survival of RGCs and inhibited the abnormal activation of microglia under acute elevated IOP conditions; the authors also reported in vitro and in vivo evidence supporting the hypothesis that scutellarin protects against hypoxic retinopathy via the inhibition of NLRP3 inflammasome signaling pathway [317].

Interestingly, the visual field protective effects of EBHM (given orally three times a day for a period of 6 months) were reported following a randomized, double blind, clinical trial in glaucoma patients with pharmacologically controlled IOP; however, further studies are needed to determine the safety and effectiveness of long-term treatment [318].

\section{Conclusions}

The rationale behind the use of nutritional supplementation in glaucoma is sustained by a significant amount of literature showing that natural compounds endowed with antioxidant, anti-inflammatory, and anti-apoptotic activities are effective in preventing RGC death in in vitro and in vivo models of retinal degeneration. However, the clinical significance of these data is yet to be proven. Indeed, in the available clinical studies, the small number of included patients, the study design heterogeneity, and the short follow-up period make it arduous to establish the clinical benefit of the treatment, and caution is needed in interpreting the results. Nevertheless, although further investigations are needed to determine their efficacy and safety, nutritional supplementation may represent an important coadjuvant in the therapeutic management of glaucoma.

Author Contributions: Conceptualization, writing and original draft preparation R.R., L.R. and A.A.; review and editing R.R., L.A.M., C.N.; supervision R.R., G.B., M.T.C. All authors have read and agreed to the published version of the manuscript.

Funding: This work was supported by SOOFT Italia S.p.A to R.R.

Conflicts of Interest: A.A., L.R., L.A.M., C.N., G.B., M.T.C. declare no conflict of interest. R.R: received a grant from SOOFT Italia SpA.

\section{References}

1. Quigley, H.A. Glaucoma. Lancet 2011, 377, 1367-1377. [CrossRef]

2. Nucci, C.; Martucci, A.; Cesareo, M.; Garaci, F.; Morrone, L.A.; Russo, R.; Corasaniti, M.T.; Bagetta, G.; Mancino, R. Links among glaucoma, neurodegenerative, and vascular diseases of the central nervous system. Prog. Brain Res. 2015, 221, 49-65. [CrossRef] [PubMed]

3. Tham, Y.C.; Li, X.; Wong, T.Y.; Quigley, H.A.; Aung, T.; Cheng, C.Y. Global prevalence of glaucoma and projections of glaucoma burden through 2040: A systematic review and meta-analysis. Ophthalmology 2014, 121, 2081-2090. [CrossRef] [PubMed]

4. Mallick, J.; Devi, L.; Malik, P.K.; Mallick, J. Update on Normal Tension Glaucoma. J. Ophthalmic. Vis. Res. 2016, 11, 204-208. [CrossRef]

5. Lusthaus, J.; Goldberg, I. Current management of glaucoma. Med. J. Aust. 2019, 210, 180-187. [CrossRef]

6. Chitranshi, N.; Dheer, Y.; Abbasi, M.; You, Y.; Graham, S.L.; Gupta, V. Glaucoma Pathogenesis and Neurotrophins: Focus on the Molecular and Genetic Basis for Therapeutic Prospects. Curr. Neuropharmacol. 2018, 16, 1018-1035. [CrossRef]

7. Adornetto, A.; Russo, R.; Parisi, V. Neuroinflammation as a target for glaucoma therapy. Neural Regen. Res. 2019, 14, 391-394. [CrossRef] 
8. Tang, B.; Li, S.; Cao, W.; Sun, X. The Association of Oxidative Stress Status with Open-Angle Glaucoma and Exfoliation Glaucoma: A Systematic Review and Meta-Analysis. J. Ophthalmol. 2019, 2019, 1803619. [CrossRef]

9. Kamel, K.; Farrell, M.; O’Brien, C. Mitochondrial dysfunction in ocular disease: Focus on glaucoma. Mitochondrion 2017, 35, 44-53. [CrossRef]

10. Russo, R.; Rotiroti, D.; Tassorelli, C.; Nucci, C.; Bagetta, G.; Bucci, M.G.; Corasaniti, M.T.; Morrone, L.A. Identification of novel pharmacological targets to minimize excitotoxic retinal damage. Int. Rev. Neurobiol. 2009, 85, 407-423. [CrossRef]

11. Russo, R.; Nucci, C.; Corasaniti, M.T.; Bagetta, G.; Morrone, L.A. Autophagy dysregulation and the fate of retinal ganglion cells in glaucomatous optic neuropathy. Prog. Brain Res. 2015, 220, 87-105. [CrossRef] [PubMed]

12. Athanasiou, D.; Aguila, M.; Bevilacqua, D.; Novoselov, S.S.; Parfitt, D.A.; Cheetham, M.E. The cell stress machinery and retinal degeneration. FEBS Lett. 2013, 587, 2008-2017. [CrossRef] [PubMed]

13. Kaur, C.; Foulds, W.S.; Ling, E.A. Hypoxia-ischemia and retinal ganglion cell damage. Clin. Ophthalmol. 2008, 2, 879-889. [CrossRef] [PubMed]

14. Gupta, N.; Yucel, Y.H. Glaucoma as a neurodegenerative disease. Curr. Opin. Ophthalmol. 2007, 18, 110-114. [CrossRef]

15. Sacca, S.C.; Cutolo, C.A.; Ferrari, D.; Corazza, P.; Traverso, C.E. The Eye, Oxidative Damage and Polyunsaturated Fatty Acids. Nutrients 2018, 10, 668. [CrossRef]

16. Sacca, S.C.; Izzotti, A.; Rossi, P.; Traverso, C. Glaucomatous outflow pathway and oxidative stress. Exp. Eye Res. 2007, 84, 389-399. [CrossRef]

17. Ghanem, A.A.; Arafa, L.F.; El-Baz, A. Oxidative stress markers in patients with primary open-angle glaucoma. Curr. Eye Res. 2010, 35, 295-301. [CrossRef]

18. Goyal, A.; Srivastava, A.; Sihota, R.; Kaur, J. Evaluation of oxidative stress markers in aqueous humor of primary open angle glaucoma and primary angle closure glaucoma patients. Curr. Eye Res. 2014, 39, 823-829. [CrossRef]

19. Abu-Amero, K.K.; Kondkar, A.A.; Mousa, A.; Osman, E.A.; Al-Obeidan, S.A. Decreased total antioxidants in patients with primary open angle glaucoma. Curr. Eye Res. 2013, 38, 959-964. [CrossRef]

20. James, A. Fat-soluble vitamins. Lancet 1995, 345, 7. [CrossRef]

21. Lykstad, J.; Sharma, S. Biochemistry, Water Soluble Vitamins; StatPearls: Treasure Island, FL, USA, 2020.

22. Veach, J. Functional dichotomy: Glutathione and vitamin $\mathrm{E}$ in homeostasis relevant to primary open-angle glaucoma. Br. J. Nutr. 2004, 91, 809-829. [CrossRef] [PubMed]

23. West, A.L.; Oren, G.A.; Moroi, S.E. Evidence for the use of nutritional supplements and herbal medicines in common eye diseases. Am. J. Ophthalmol. 2006, 141, 157-166. [CrossRef] [PubMed]

24. Lawler, T.; Liu, Y.; Christensen, K.; Vajaranant, T.S.; Mares, J. Dietary Antioxidants, Macular Pigment, and Glaucomatous Neurodegeneration: A Review of the Evidence. Nutrients 2019, 11, 1002. [CrossRef]

25. Scuteri, D.; Rombolà, L.; Watanabe, C.; Sakurada, S.; Corasaniti, M.T.; Bagetta, G.; Bagetta, G.; Tonin, P.; Russo, R.; Nucci, C.; et al. Impact of nutraceuticals on glaucoma: A systematic review. Prog. Brain Res. 2020, 257, 141-154. [PubMed]

26. Kang, J.H.; Pasquale, L.R.; Willett, W.; Rosner, B.; Egan, K.M.; Faberowski, N.; Hankinson, S.E. Antioxidant intake and primary open-angle glaucoma: A prospective study. Am. J. Epidemiol. 2003, 158, 337-346. [CrossRef] [PubMed]

27. Coleman, A.L.; Stone, K.L.; Kodjebacheva, G.; Yu, F.; Pedula, K.L.; Ensrud, K.E.; Cauley, J.A.; Hochberg, M.C.; Topouzis, F.; Badala, F.; et al. Glaucoma risk and the consumption of fruits and vegetables among older women in the study of osteoporotic fractures. Am. J. Ophthalmol. 2008, 145, 1081-1089. [CrossRef]

28. Giaconi, J.A.; Yu, F.; Stone, K.L.; Pedula, K.L.; Ensrud, K.E.; Cauley, J.A.; Hochberg, M.C.; Coleman, A.L. Study of Osteoporotic Fractures Research Group. The association of consumption of fruits/vegetables with decreased risk of glaucoma among older African-American women in the study of osteoporotic fractures. Am. J. Ophthalmol. 2012, 154, 635-644. [CrossRef]

29. Ramdas, W.D.; Wolfs, R.C.; Kiefte-de Jong, J.C.; Hofman, A.; de Jong, P.T.; Vingerling, J.R.; Jansonius, N.M. Nutrient intake and risk of open-angle glaucoma: The Rotterdam Study. Eur. J. Epidemiol. 2012, 27, 385-393. [CrossRef] 
30. Yoserizal, M.; Hirooka, K.; Yoneda, M.; Ohno, H.; Kobuke, K.; Kawano, R.; Kiuchi, Y. Associations of nutrient intakes with glaucoma among Japanese Americans. Medicine 2019, 98, e18314. [CrossRef]

31. Garcia-Medina, J.J.; Garcia-Medina, M.; Garrido-Fernandez, P.; Galvan-Espinosa, J.; Garcia-Maturana, C.; Zanon-Moreno, V.; Pinazo-Duran, M.D. A two-year follow-up of oral antioxidant supplementation in primary open-angle glaucoma: An open-label, randomized, controlled trial. Acta Ophthalmol. 2015, 93, 546-554. [CrossRef]

32. Wang, Y.E.; Tseng, V.L.; Yu, F.; Caprioli, J.; Coleman, A.L. Association of Dietary Fatty Acid Intake with Glaucoma in the United States. JAMA Ophthalmol. 2018, 136, 141-147. [CrossRef] [PubMed]

33. Yuki, K.; Murat, D.; Kimura, I.; Ohtake, Y.; Tsubota, K. Reduced-serum vitamin C and increased uric acid levels in normal-tension glaucoma. Graefes Arch. Clin. Exp. Ophthalmol. 2010, 248, 243-248. [CrossRef] [PubMed]

34. Li, J.; Xu, F.; Zeng, R.; Gong, H.; Lan, Y. Plasma Homocysteine, Serum Folic Acid, Serum Vitamin B12, Serum Vitamin B6, MTHFR, and Risk of Normal-Tension Glaucoma. J. Glaucoma 2016, 25, e94-e98. [CrossRef] [PubMed]

35. Turgut, B.; Kaya, M.; Arslan, S.; Demir, T.; Guler, M.; Kaya, M.K. Levels of circulating homocysteine, vitamin B6, vitamin B12, and folate in different types of open-angle glaucoma. Clin. Interv. Aging 2010, 5, 133-139. [CrossRef]

36. Das, B.C.; Thapa, P.; Karki, R.; Das, S.; Mahapatra, S.; Liu, T.C.; Torregroza, I.; Wallace, D.P.; Kambhampati, S.; Van Veldhuizen, P.; et al. Retinoic acid signaling pathways in development and diseases. Bioorganic Med. Chem. 2014, 22, 673-683. [CrossRef]

37. Engin, K.N.; Yemisci, B.; Yigit, U.; Agachan, A.; Coskun, C. Variability of serum oxidative stress biomarkers relative to biochemical data and clinical parameters of glaucoma patients. Mol. Vis. 2010, 16, 1260-1271. [PubMed]

38. Lopez-Riquelme, N.; Villalba, C.; Tormo, C.; Belmonte, A.; Fernandez, C.; Torralba, G.; Hernandez, F. Endothelin-1 levels and biomarkers of oxidative stress in glaucoma patients. Int. Ophthalmol. 2015, 35, 527-532. [CrossRef] [PubMed]

39. Wang, S.Y.; Singh, K.; Lin, S.C. Glaucoma and vitamins A, C, and E supplement intake and serum levels in a population-based sample of the United States. Eye 2013, 27, 487-494. [CrossRef] [PubMed]

40. Manzetti, S.; Zhang, J.; van der Spoel, D. Thiamin function, metabolism, uptake, and transport. Biochemistry 2014, 53, 821-835. [CrossRef]

41. Gratton, S.M.; Lam, B.L. Visual loss and optic nerve head swelling in thiamine deficiency without prolonged dietary deficiency. Clin. Ophthalmol. 2014, 8, 1021-1024. [CrossRef]

42. Pinto, J.T.; Zempleni, J. Riboflavin. Adv. Nutr. 2016, 7, 973-975. [CrossRef] [PubMed]

43. Gasperi, V.; Sibilano, M.; Savini, I.; Catani, M.V. Niacin in the Central Nervous System: An Update of Biological Aspects and Clinical Applications. Int. J. Mol. Sci. 2019, 20, 974. [CrossRef] [PubMed]

44. Verdin, E. NAD(+) in aging, metabolism, and neurodegeneration. Science 2015, 350, 1208-1213. [CrossRef]

45. Williams, P.A.; Harder, J.M.; Foxworth, N.E.; Cochran, K.E.; Philip, V.M.; Porciatti, V.; Smithies, O.; John, S.W. Vitamin B3 modulates mitochondrial vulnerability and prevents glaucoma in aged mice. Science 2017, 355, 756-760. [CrossRef] [PubMed]

46. Mack, T.G.; Reiner, M.; Beirowski, B.; Mi, W.; Emanuelli, M.; Wagner, D.; Thomson, D.; Gillingwater, T.; Court, F.; Conforti, L.; et al. Wallerian degeneration of injured axons and synapses is delayed by a Ube4b/Nmnat chimeric gene. Nat. Neurosci. 2001, 4, 1199-1206. [CrossRef] [PubMed]

47. Liebmann, J.M.; Cioffi, G.A. Nicking Glaucoma with Nicotinamide? N. Engl. J. Med. 2017, 376, $2079-2081$. [CrossRef]

48. Williams, P.A.; Harder, J.M.; Cardozo, B.H.; Foxworth, N.E.; John, S.W.M. Nicotinamide treatment robustly protects from inherited mouse glaucoma. Commun. Integr. Biol. 2018, 11, e1356956. [CrossRef]

49. Kouassi Nzoughet, J.; Chao de la Barca, J.M.; Guehlouz, K.; Leruez, S.; Coulbault, L.; Allouche, S.; Bocca, C.; Muller, J.; Amati-Bonneau, P.; Gohier, P.; et al. Nicotinamide Deficiency in Primary Open-Angle Glaucoma. Investig. Ophthalmol. Vis. Sci. 2019, 60, 2509-2514. [CrossRef]

50. Hui, F.; Tang, J.; Williams, P.A.; McGuinness, M.B.; Hadoux, X.; Casson, R.J.; Coote, M.; Trounce, I.A.; Martin, K.R.; van Wijngaarden, P.; et al. Improvement in inner retinal function in glaucoma with nicotinamide (vitamin B3) supplementation: A crossover randomized clinical trial. Clin. Exp. Ophthalmol. 2020. [CrossRef] 
51. Mooney, S.; Leuendorf, J.E.; Hendrickson, C.; Hellmann, H. Vitamin B6: A long known compound of surprising complexity. Molecules 2009, 14, 329-351. [CrossRef]

52. Stover, P.J.; Field, M.S. Vitamin B-6. Adv. Nutr. 2015, 6, 132-133. [CrossRef] [PubMed]

53. Tas, S.; Sarandol, E.; Dirican, M. Vitamin B6 supplementation improves oxidative stress and enhances serum paraoxonase/arylesterase activities in streptozotocin-induced diabetic rats. Sci. World J. 2014, 2014, 351598. [CrossRef] [PubMed]

54. Ianovskaia, N.P.; Shtol'ko, V.N.; Burlakova, E.B. Effect of low doses of emoxipine and pyridoxine hydrochloride on the status of patients with cataract and glaucoma. Bull. Exp. Biol. Med. 1993, 115, 479-481.

55. Ho, P.I.; Ashline, D.; Dhitavat, S.; Ortiz, D.; Collins, S.C.; Shea, T.B.; Rogers, E. Folate deprivation induces neurodegeneration: Roles of oxidative stress and increased homocysteine. Neurobiol. Dis. 2003, 14, 32-42. [CrossRef]

56. Navneet, S.; Zhao, J.; Wang, J.; Mysona, B.; Barwick, S.; Kaidery, N.A.; Saul, A.; Kaddour-Djebbar, I.; Bollag, W.B.; Thomas, B.; et al. Hyperhomocysteinemia-induced death of retinal ganglion cells: The role of Muller glial cells and NRF2. Redox Biol. 2019, 24, 101199. [CrossRef]

57. Roedl, J.B.; Bleich, S.; Reulbach, U.; von Ahsen, N.; Schlotzer-Schrehardt, U.; Rejdak, R.; Naumann, G.O.; Kruse, F.E.; Kornhuber, J.; Junemann, A.G. Homocysteine levels in aqueous humor and plasma of patients with primary open-angle glaucoma. J. Neural Transm. 2007, 114, 445-450. [CrossRef]

58. Ghanem, A.A.; Mady, S.M.; El Awady, H.E.; Arafa, L.F. Homocysteine and hydroxyproline levels in patients with primary open-angle glaucoma. Curr. Eye Res. 2012, 37, 712-718. [CrossRef]

59. Leibovitzh, H.; Cohen, E.; Levi, A.; Kramer, M.; Shochat, T.; Goldberg, E.; Krause, I. Relationship between homocysteine and intraocular pressure in men and women: A population-based study. Medicine 2016, 95, e4858. [CrossRef]

60. Rebeille, F.; Ravanel, S.; Marquet, A.; Mendel, R.R.; Webb, M.E.; Smith, A.G.; Warren, M.J. Roles of vitamins B5, B8, B9, B12 and molybdenum cofactor at cellular and organismal levels. Nat. Prod. Rep. 2007, 24, 949-962. [CrossRef]

61. Cumurcu, T.; Sahin, S.; Aydin, E. Serum homocysteine, vitamin B 12 and folic acid levels in different types of glaucoma. BMC Ophthalmol. 2006, 6, 6. [CrossRef]

62. Chavala, S.H.; Kosmorsky, G.S.; Lee, M.K.; Lee, M.S. Optic neuropathy in vitamin B12 deficiency. Eur. J. Intern. Med. 2005, 16, 447-448. [CrossRef]

63. Briani, C.; Dalla Torre, C.; Citton, V.; Manara, R.; Pompanin, S.; Binotto, G.; Adami, F. Cobalamin deficiency: Clinical picture and radiological findings. Nutrients 2013, 5, 4521-4539. [CrossRef]

64. Turkyilmaz, K.; Oner, V.; Ozkasap, S.; Sekeryapan, B.; Dereci, S.; Durmus, M. Peripapillary retinal nerve fiber layer thickness in children with iron deficiency anemia. Eur. J. Ophthalmol. 2013, 23, 217-222. [CrossRef]

65. Kang, J.H.; Loomis, S.J.; Wiggs, J.L.; Willett, W.C.; Pasquale, L.R. A prospective study of folate, vitamin B(6), and vitamin $\mathrm{B}(1)(2)$ intake in relation to exfoliation glaucoma or suspected exfoliation glaucoma. JAMA Ophthalmol. 2014, 132, 549-559. [CrossRef]

66. Padayatty, S.J.; Katz, A.; Wang, Y.; Eck, P.; Kwon, O.; Lee, J.H.; Chen, S.; Corpe, C.; Dutta, A.; Dutta, S.K.; et al. Vitamin $C$ as an antioxidant: Evaluation of its role in disease prevention. J. Am. Coll. Nutr. 2003, 22, 18-35. [CrossRef]

67. Lee, P.; Lam, K.W.; Lai, M. Aqueous humor ascorbate concentration and open-angle glaucoma. Arch. Ophthalmol. 1977, 95, 308-310. [CrossRef] [PubMed]

68. Aleksidze, A.T.; Beradze, I.N.; Golovachev, O.G. Effect of the ascorbic acid of the aqueous humor on the lipid peroxidation process in the eye in primary open-angle glaucoma. Oftalmol. Zhurnal 1989, 2, 114-116.

69. Leite, M.T.; Prata, T.S.; Kera, C.Z.; Miranda, D.V.; de Moraes Barros, S.B.; Melo, L.A., Jr. Ascorbic acid concentration is reduced in the secondary aqueous humour of glaucomatous patients. Clin. Exp. Ophthalmol. 2009, 37, 402-406. [CrossRef] [PubMed]

70. Xu, P.; Lin, Y.; Porter, K.; Liton, P.B. Ascorbic acid modulation of iron homeostasis and lysosomal function in trabecular meshwork cells. J. Ocul. Pharmacol. Ther. 2014, 30, 246-253. [CrossRef] [PubMed]

71. Schachtschabel, D.O.; Binninger, E. Stimulatory effects of ascorbic acid on hyaluronic acid synthesis of in vitro cultured normal and glaucomatous trabecular meshwork cells of the human eye. Z. Gerontol. 1993, $26,243-246$.

72. Liu, K.M.; Swann, D.; Lee, P.; Lam, K.W. Inhibition of oxidative degradation of hyaluronic acid by uric acid. Curr. Eye Res. 1984, 3, 1049-1053. [CrossRef] [PubMed] 
73. Hysi, P.G.; Khawaja, A.P.; Menni, C.; Tamraz, B.; Wareham, N.; Khaw, K.T.; Foster, P.J.; Benet, L.Z.; Spector, T.D.; Hammond, C.J. Ascorbic acid metabolites are involved in intraocular pressure control in the general population. Redox Biol. 2019, 20, 349-353. [CrossRef] [PubMed]

74. Silva, M.C.; Furlanetto, T.W. Intestinal absorption of vitamin D: A systematic review. Nutr. Rev. 2018, 76, 60-76. [CrossRef] [PubMed]

75. Hossein-nezhad, A.; Holick, M.F. Vitamin D for health: A global perspective. Mayo Clin. Proc. 2013, 88, 720-755. [CrossRef] [PubMed]

76. Goncalves, A.; Milea, D.; Gohier, P.; Jallet, G.; Leruez, S.; Baskaran, M.; Aung, T.; Annweiler, C. Serum vitamin $\mathrm{D}$ status is associated with the presence but not the severity of primary open angle glaucoma. Maturitas 2015, 81, 470-474. [CrossRef]

77. Burgess, L.G.; Uppal, K.; Walker, D.I.; Roberson, R.M.; Tran, V.; Parks, M.B.; Wade, E.A.; May, A.T.; Umfress, A.C.; Jarrell, K.L.; et al. Metabolome-Wide Association Study of Primary Open Angle Glaucoma. Investig. Ophthalmol. Vis. Sci. 2015, 56, 5020-5028. [CrossRef]

78. Lv, Y.; Yao, Q.; Ma, W.; Liu, H.; Ji, J.; Li, X. Associations of vitamin D deficiency and vitamin D receptor (Cdx-2, Fok I, Bsm I and Taq I) polymorphisms with the risk of primary open-angle glaucoma. BMC Ophthalmol. 2016, 16, 1-7. [CrossRef]

79. Yoo, T.K.; Oh, E.; Hong, S. Is vitamin D status associated with open-angle glaucoma? A cross-sectional study from South Korea. Public Health Nutr. 2014, 17, 833-843. [CrossRef]

80. Ayyagari, R.; Chen, Y.I.; Zangwill, L.M.; Holman, M.; Dirkes, K.; Hai, Y.; Arzumanyan, Z.; Slight, R.; Hammel, N.; Girkin, C.A.; et al. Association of severity of primary open-angle glaucoma with serum vitamin D levels in patients of African descent. Mol. Vis. 2019, 25, 438-445.

81. Vukovic Arar, Z.; Knezevic Pravecek, M.; Miskic, B.; Vatavuk, Z.; Vukovic Rodriguez, J.; Sekelj, S. Association between Serum Vitamin D Level and Glaucoma in Women. Acta Clin. Croat. 2016, 55, 203-208. [CrossRef]

82. Gye, H.J.; Kim, J.M.; Yoo, C.; Shim, S.H.; Won, Y.S.; Sung, K.C.; Lee, M.Y.; Park, K.H. Relationship between high serum ferritin level and glaucoma in a South Korean population: The Kangbuk Samsung health study. Br. J. Ophthalmol. 2016, 100, 1703-1707. [CrossRef] [PubMed]

83. Kutuzova, G.D.; Gabelt, B.T.; Kiland, J.A.; Hennes-Beann, E.A.; Kaufman, P.L.; DeLuca, H.F. 1alpha,25-Dihydroxyvitamin D(3) and its analog, 2-methylene-19-nor-(20S)-1alpha,25-dihydroxyvitamin D(3) (2MD), suppress intraocular pressure in non-human primates. Arch. Biochem. Biophys. 2012, 518, 53-60. [CrossRef] [PubMed]

84. Krefting, E.A.; Jorde, R.; Christoffersen, T.; Grimnes, G. Vitamin D and intraocular pressure-results from a case-control and an intervention study. Acta Ophthalmol. 2014, 92, 345-349. [CrossRef]

85. Han, S.N.; Meydani, S.N. Impact of vitamin E on immune function and its clinical implications. Expert Rev. Clin. Immunol. 2006, 2, 561-567. [CrossRef] [PubMed]

86. Ko, M.L.; Peng, P.H.; Hsu, S.Y.; Chen, C.F. Dietary deficiency of vitamin E aggravates retinal ganglion cell death in experimental glaucoma of rats. Curr. Eye Res. 2010, 35, 842-849. [CrossRef]

87. Zanon-Moreno, V.; Asensio-Marquez, E.M.; Ciancotti-Oliver, L.; Garcia-Medina, J.J.; Sanz, P.; Ortega-Azorin, C.; Pinazo-Duran, M.D.; Ordovas, J.M.; Corella, D. Effects of polymorphisms in vitamin E-, vitamin $\mathrm{C}-$, and glutathione peroxidase-related genes on serum biomarkers and associations with glaucoma. Mol. Vis. 2013, 19, 231-242.

88. Engin, K.N.; Engin, G.; Kucuksahin, H.; Oncu, M.; Engin, G.; Guvener, B. Clinical evaluation of the neuroprotective effect of alpha-tocopherol against glaucomatous damage. Eur. J. Ophthalmol. 2007, 17, 528-533. [CrossRef] [PubMed]

89. Hillgartner, F.B.; Salati, L.M.; Goodridge, A.G. Physiological and molecular mechanisms involved in nutritional regulation of fatty acid synthesis. Physiol. Rev. 1995, 75, 47-76. [CrossRef]

90. Saini, R.K.; Keum, Y.S. Omega-3 and omega-6 polyunsaturated fatty acids: Dietary sources, metabolism, and significance-A review. Life Sci. 2018, 203, 255-267. [CrossRef]

91. Patterson, E.; Wall, R.; Fitzgerald, G.F.; Ross, R.P.; Stanton, C. Health implications of high dietary omega-6 polyunsaturated Fatty acids. J. Nutr. Metab. 2012, 2012, 539426. [CrossRef]

92. Kim, H.Y.; Spector, A.A. N-Docosahexaenoylethanolamine: A neurotrophic and neuroprotective metabolite of docosahexaenoic acid. Mol. Asp. Med. 2018, 64, 34-44. [CrossRef] [PubMed]

93. SanGiovanni, J.P.; Chew, E.Y. The role of omega-3 long-chain polyunsaturated fatty acids in health and disease of the retina. Prog. Retin. Eye Res. 2005, 24, 87-138. [CrossRef] [PubMed] 
94. Bazan, N.G. Cell survival matters: Docosahexaenoic acid signaling, neuroprotection and photoreceptors. Trends Neurosci. 2006, 29, 263-271. [CrossRef]

95. Galli, C.; Calder, P.C. Effects of fat and fatty acid intake on inflammatory and immune responses: A critical review. Ann. Nutr. Metab. 2009, 55, 123-139. [CrossRef]

96. Den Ruijter, H.M.; Berecki, G.; Opthof, T.; Verkerk, A.O.; Zock, P.L.; Coronel, R. Pro- and antiarrhythmic properties of a diet rich in fish oil. Cardiovasc. Res. 2007, 73, 316-325. [CrossRef] [PubMed]

97. Wall, R.; Ross, R.P.; Fitzgerald, G.F.; Stanton, C. Fatty acids from fish: The anti-inflammatory potential of long-chain omega-3 fatty acids. Nutr. Rev. 2010, 68, 280-289. [CrossRef] [PubMed]

98. Wang, H.; Li, Q.; Zhu, Y.; Zhang, X. Omega-3 Polyunsaturated Fatty Acids: Versatile Roles in Blood Pressure Regulation. Antioxid. Redox Signal. 2020. [CrossRef]

99. Giacobbe, J.; Benoiton, B.; Zunszain, P.; Pariante, C.M.; Borsini, A. The Anti-Inflammatory Role of Omega-3 Polyunsaturated Fatty Acids Metabolites in Pre-Clinical Models of Psychiatric, Neurodegenerative, and Neurological Disorders. Front. Psychiatry 2020, 11, 122. [CrossRef]

100. Hooper, C.; De Souto Barreto, P.; Pahor, M.; Weiner, M.; Vellas, B. The Relationship of Omega 3 Polyunsaturated Fatty Acids in Red Blood Cell Membranes with Cognitive Function and Brain Structure: A Review Focussed on Alzheimer's Disease. J. Prev. Alzheimers Dis. 2018, 5, 78-84. [CrossRef]

101. Liao, Y.; Xie, B.; Zhang, H.; He, Q.; Guo, L.; Subramaniapillai, M.; Fan, B.; Lu, C.; McLntyer, R.S. Efficacy of omega-3 PUFAs in depression: A meta-analysis. Transl. Psychiatry 2019, 9, 1-9. [CrossRef]

102. Kang, J.H.; Pasquale, L.R.; Willett, W.C.; Rosner, B.A.; Egan, K.M.; Faberowski, N.; Hankinson, S.E. Dietary fat consumption and primary open-angle glaucoma. Am. J. Clin. Nutr. 2004, 79, 755-764. [CrossRef] [PubMed]

103. de Arcelus, M.P.; Toledo, E.; Martinez-Gonzalez, M.A.; Sayon-Orea, C.; Gea, A.; Moreno-Montanes, J. Omega 3:6 ratio intake and incidence of glaucoma: The SUN cohort. Clin. Nutr. 2014, 33, 1041-1045. [CrossRef] [PubMed]

104. Nguyen, C.T.; Bui, B.V.; Sinclair, A.J.; Vingrys, A.J. Dietary omega 3 fatty acids decrease intraocular pressure with age by increasing aqueous outflow. Investig. Ophthalmol. Vis. Sci. 2007, 48, 756-762. [CrossRef] [PubMed]

105. Downie, L.E.; Vingrys, A.J. Oral Omega-3 Supplementation Lowers Intraocular Pressure in Normotensive Adults. Transl. Vis. Sci. Technol. 2018, 7, 1. [CrossRef] [PubMed]

106. Schnebelen, C.; Pasquis, B.; Salinas-Navarro, M.; Joffre, C.; Creuzot-Garcher, C.P.; Vidal-Sanz, M.; Bron, A.M.; Bretillon, L.; Acar, N. A dietary combination of omega-3 and omega-6 polyunsaturated fatty acids is more efficient than single supplementations in the prevention of retinal damage induced by elevation of intraocular pressure in rats. Graefes Arch. Clin. Exp. Ophthalmol. 2009, 247, 1191-1203. [CrossRef] [PubMed]

107. Nguyen, C.T.; Vingrys, A.J.; Bui, B.V. Dietary omega-3 fatty acids and ganglion cell function. Investig. Ophthalmol. Vis. Sci. 2008, 49, 3586-3594. [CrossRef] [PubMed]

108. Nguyen, C.T.; Vingrys, A.J.; Bui, B.V. Dietary omega-3 deficiency and IOP insult are additive risk factors for ganglion cell dysfunction. J. Glaucoma 2013, 22, 269-277. [CrossRef] [PubMed]

109. Inman, D.M.; Lambert, W.S.; Calkins, D.J.; Horner, P.J. Alpha-Lipoic acid antioxidant treatment limits glaucoma-related retinal ganglion cell death and dysfunction. PLoS ONE 2013, 8, e65389. [CrossRef]

110. Kalogerou, M.; Kolovos, P.; Prokopiou, E.; Papagregoriou, G.; Deltas, C.; Malas, S.; Georgiou, T. Omega-3 fatty acids protect retinal neurons in the DBA/2J hereditary glaucoma mouse model. Exp. Eye Res. 2018, 167, 128-139. [CrossRef]

111. Petrosino, S.; Di Marzo, V. The pharmacology of palmitoylethanolamide and first data on the therapeutic efficacy of some of its new formulations. Br. J. Pharmacol. 2017, 174, 1349-1365. [CrossRef]

112. Keppel Hesselink, J.M.; Costagliola, C.; Fakhry, J.; Kopsky, D.J. Palmitoylethanolamide, a Natural Retinoprotectant: Its Putative Relevance for the Treatment of Glaucoma and Diabetic Retinopathy. J. Ophthalmol. 2015, 2015, 430596. [CrossRef]

113. Okamoto, Y.; Morishita, J.; Wang, J.; Schmid, P.C.; Krebsbach, R.J.; Schmid, H.H.; Ueda, N. Mammalian cells stably overexpressing $\mathrm{N}$-acylphosphatidylethanolamine-hydrolysing phospholipase D exhibit significantly decreased levels of N-acylphosphatidylethanolamines. Biochem. J. 2005, 389, 241-247. [CrossRef] [PubMed]

114. Cravatt, B.F.; Giang, D.K.; Mayfield, S.P.; Boger, D.L.; Lerner, R.A.; Gilula, N.B. Molecular characterization of an enzyme that degrades neuromodulatory fatty-acid amides. Nature 1996, 384, 83-87. [CrossRef] 
115. Ueda, N.; Yamanaka, K.; Yamamoto, S. Purification and characterization of an acid amidase selective for $\mathrm{N}$-palmitoylethanolamine, a putative endogenous anti-inflammatory substance. J. Biol. Chem. 2001, 276, 35552-35557. [CrossRef]

116. Di Marzo, V.; Fontana, A.; Cadas, H.; Schinelli, S.; Cimino, G.; Schwartz, J.C.; Piomelli, D. Formation and inactivation of endogenous cannabinoid anandamide in central neurons. Nature 1994, 372, 686-691. [CrossRef] [PubMed]

117. Ross, R.A. The enigmatic pharmacology of GPR55. Trends Pharmacol. Sci. 2009, 30, 156-163. [CrossRef]

118. Pistis, M.; Melis, M. From surface to nuclear receptors: The endocannabinoid family extends its assets. Curr. Med. Chem. 2010, 17, 1450-1467. [CrossRef]

119. Chen, J.; Matias, I.; Dinh, T.; Lu, T.; Venezia, S.; Nieves, A.; Woodward, D.F.; Di Marzo, V. Finding of endocannabinoids in human eye tissues: Implications for glaucoma. Biochem. Biophys. Res. Commun. 2005, 330, 1062-1067. [CrossRef] [PubMed]

120. Pescosolido, N.; Librando, A.; Puzzono, M.; Nebbioso, M. Palmitoylethanolamide effects on intraocular pressure after Nd:YAG laser iridotomy: An experimental clinical study. J. Ocul. Pharmacol. Ther. 2011, 27, 629-635. [CrossRef] [PubMed]

121. Strobbe, E.; Cellini, M.; Campos, E.C. Effectiveness of palmitoylethanolamide on endothelial dysfunction in ocular hypertensive patients: A randomized, placebo-controlled cross-over study. Investig. Ophthalmol. Vis. Sci. 2013, 54, 968-973. [CrossRef]

122. Gagliano, C.; Ortisi, E.; Pulvirenti, L.; Reibaldi, M.; Scollo, D.; Amato, R.; Avitabile, T.; Longo, A. Ocular hypotensive effect of oral palmitoyl-ethanolamide: A clinical trial. Investig. Ophthalmol. Vis. Sci. 2011, 52, 6096-6100. [CrossRef]

123. Costagliola, C.; Romano, M.R.; dell'Omo, R.; Russo, A.; Mastropasqua, R.; Semeraro, F. Effect of palmitoylethanolamide on visual field damage progression in normal tension glaucoma patients: Results of an open-label six-month follow-up. J. Med. Food 2014, 17, 949-954. [CrossRef]

124. Rossi, G.C.M.; Scudeller, L.; Lumini, C.; Bettio, F.; Picasso, E.; Ruberto, G.; Briola, A.; Mirabile, A.; Paviglianiti, A.; Pasinetti, G.M.; et al. Effect of palmitoylethanolamide on inner retinal function in glaucoma: A randomized, single blind, crossover, clinical trial by pattern-electroretinogram. Sci. Rep. 2020, 10, 10468. [CrossRef] [PubMed]

125. Romano, M.R.; Lograno, M.D. Involvement of the peroxisome proliferator-activated receptor (PPAR) alpha in vascular response of endocannabinoids in the bovine ophthalmic artery. Eur. J. Pharmacol. 2012, 683, 197-203. [CrossRef]

126. Gilbert, G.L.; Kim, H.J.; Waataja, J.J.; Thayer, S.A. Delta9-tetrahydrocannabinol protects hippocampal neurons from excitotoxicity. Brain Res. 2007, 1128, 61-69. [CrossRef] [PubMed]

127. Rapino, C.; Tortolani, D.; Scipioni, L.; Maccarrone, M. Neuroprotection by (endo)Cannabinoids in Glaucoma and Retinal Neurodegenerative Diseases. Curr. Neuropharmacol. 2018, 16, 959-970. [CrossRef] [PubMed]

128. Nucci, C.; Gasperi, V.; Tartaglione, R.; Cerulli, A.; Terrinoni, A.; Bari, M.; De Simone, C.; Agro, A.F.; Morrone, L.A.; Corasaniti, M.T.; et al. Involvement of the endocannabinoid system in retinal damage after high intraocular pressure-induced ischemia in rats. Investig. Ophthalmol. Vis. Sci. 2007, 48, 2997-3004. [CrossRef] [PubMed]

129. Yazulla, S. Endocannabinoids in the retina: From marijuana to neuroprotection. Prog. Retin. Eye Res. 2008, 27, 501-526. [CrossRef]

130. Ben-Shabat, S.; Fride, E.; Sheskin, T.; Tamiri, T.; Rhee, M.H.; Vogel, Z.; Bisogno, T.; De Petrocellis, L.; Di Marzo, V.; Mechoulam, R. An entourage effect: Inactive endogenous fatty acid glycerol esters enhance 2-arachidonoyl-glycerol cannabinoid activity. Eur. J. Pharmacol. 1998, 353, 23-31. [CrossRef]

131. Emet, M.; Ozcan, H.; Ozel, L.; Yayla, M.; Halici, Z.; Hacimuftuoglu, A. A Review of Melatonin, Its Receptors and Drugs. Eurasian J. Med. 2016, 48, 135-141. [CrossRef] [PubMed]

132. Lundmark, P.O.; Pandi-Perumal, S.R.; Srinivasan, V.; Cardinali, D.P. Role of melatonin in the eye and ocular dysfunctions. Vis. Neurosci. 2006, 23, 853-862. [CrossRef] [PubMed]

133. Baraboi, V.A. Antioxidant and biological activity of melatonin. Ukrains' kyi Biokhimichnyi Zhurnal 2000, 72, 5-11.

134. Srinivasan, V.; Pandi-Perumal, S.R.; Maestroni, G.J.; Esquifino, A.I.; Hardeland, R.; Cardinali, D.P. Role of melatonin in neurodegenerative diseases. Neurotox. Res. 2005, 7, 293-318. [CrossRef] [PubMed] 
135. Belforte, N.A.; Moreno, M.C.; de Zavalia, N.; Sande, P.H.; Chianelli, M.S.; Keller Sarmiento, M.I.; Rosenstein, R.E. Melatonin: A novel neuroprotectant for the treatment of glaucoma. J. Pineal Res. 2010, 48, 353-364. [CrossRef]

136. Del Valle Bessone, C.; Fajreldines, H.D.; de Barboza, G.E.D.; de Talamoni, N.G.T.; Allemandi, D.A.; Carpentieri, A.R.; Quinteros, D.A. Protective role of melatonin on retinal ganglionar cell: In vitro an in vivo evidences. Life Sci. 2019, 218, 233-240. [CrossRef]

137. Park, S.W.; Lee, H.S.; Sung, M.S.; Kim, S.J. The effect of melatonin on retinal ganglion cell survival in ischemic retina. Chonnam Med. J. 2012, 48, 116-122. [CrossRef]

138. Kaur, C.; Sivakumar, V.; Robinson, R.; Foulds, W.S.; Luu, C.D.; Ling, E.A. Neuroprotective effect of melatonin against hypoxia-induced retinal ganglion cell death in neonatal rats. J. Pineal Res. 2013, 54, 190-206. [CrossRef]

139. Kilic, E.; Hermann, D.M.; Isenmann, S.; Bahr, M. Effects of pinealectomy and melatonin on the retrograde degeneration of retinal ganglion cells in a novel model of intraorbital optic nerve transection in mice. J. Pineal Res. 2002, 32, 106-111. [CrossRef]

140. Pintor, J.; Pelaez, T.; Hoyle, C.H.; Peral, A. Ocular hypotensive effects of melatonin receptor agonists in the rabbit: Further evidence for an MT3 receptor. Br. J. Pharmacol. 2003, 138, 831-836. [CrossRef]

141. Crooke, A.; Huete-Toral, F.; Martinez-Aguila, A.; Martin-Gil, A.; Pintor, J. Melatonin and its analog 5-methoxycarbonylamino- $\mathrm{N}$-acetyltryptamine potentiate adrenergic receptor-mediated ocular hypotensive effects in rabbits: Significance for combination therapy in glaucoma. J. Pharmacol. Exp. Ther. 2013, 346, 138-145. [CrossRef]

142. Martinez-Aguila, A.; Fonseca, B.; Bergua, A.; Pintor, J. Melatonin analogue agomelatine reduces rabbit's intraocular pressure in normotensive and hypertensive conditions. Eur. J. Pharmacol. 2013, 701, 213-217. [CrossRef] [PubMed]

143. Serle, J.B.; Wang, R.F.; Peterson, W.M.; Plourde, R.; Yerxa, B.R. Effect of 5-MCA-NAT, a putative melatonin MT3 receptor agonist, on intraocular pressure in glaucomatous monkey eyes. J. Glaucoma 2004, 13, 385-388. [CrossRef] [PubMed]

144. Martinez-Aguila, A.; Fonseca, B.; de Lara, M.J.P.; Pintor, J. Effect of Melatonin and 5-Methoxycarbonylamino-N-Acetyltryptamine on the Intraocular Pressure of Normal and Glaucomatous Mice. J. Pharmacol. Exp. Ther. 2016, 357, 293-299. [CrossRef] [PubMed]

145. Samples, J.R.; Krause, G.; Lewy, A.J. Effect of melatonin on intraocular pressure. Curr. Eye Res. 1988, 7 , 649-653. [CrossRef] [PubMed]

146. Ismail, S.A.; Mowafi, H.A. Melatonin provides anxiolysis, enhances analgesia, decreases intraocular pressure, and promotes better operating conditions during cataract surgery under topical anesthesia. Anesth. Analg. 2009, 108, 1146-1151. [CrossRef] [PubMed]

147. Carracedo-Rodriguez, G.; Martinez-Aguila, A.; Rodriguez-Pomar, C.; Bodas-Romero, J.; Sanchez-Naves, J.; Pintor, J. Effect of nutritional supplement based on melatonin on the intraocular pressure in normotensive subjects. Int. Ophthalmol. 2020, 40, 419-422. [CrossRef] [PubMed]

148. Pescosolido, N.; Gatto, V.; Stefanucci, A.; Rusciano, D. Oral treatment with the melatonin agonist agomelatine lowers the intraocular pressure of glaucoma patients. Ophthalmic Physiol. Opt. 2015, 35, 201-205. [CrossRef] [PubMed]

149. Alcantara-Contreras, S.; Baba, K.; Tosini, G. Removal of melatonin receptor type 1 increases intraocular pressure and retinal ganglion cells death in the mouse. Neurosci. Lett. 2011, 494, 61-64. [CrossRef]

150. Baba, K.; Pozdeyev, N.; Mazzoni, F.; Contreras-Alcantara, S.; Liu, C.; Kasamatsu, M.; Martinez-Merlos, T.; Strettoi, E.; Iuvone, P.M.; Tosini, G. Melatonin modulates visual function and cell viability in the mouse retina via the MT1 melatonin receptor. Proc. Natl. Acad. Sci. USA 2009, 106, 15043-15048. [CrossRef]

151. Ma, X.P.; Shen, M.Y.; Shen, G.L.; Qi, Q.R.; Sun, X.H. Melatonin concentrations in serum of primary glaucoma patients. Int. J. Ophthalmol. 2018, 11, 1337-1341. [CrossRef] [PubMed]

152. D’Orlando, K.J.; Sandage, B.W., Jr. Citicoline (CDP-choline): Mechanisms of action and effects in ischemic brain injury. Neurol. Res. 1995, 17, 281-284. [CrossRef] [PubMed]

153. Roberti, G.; Tanga, L.; Michelessi, M.; Quaranta, L.; Parisi, V.; Manni, G.; Oddone, F. Cytidine 5 -Diphosphocholine (Citicoline) in Glaucoma: Rationale of Its Use, Current Evidence and Future Perspectives. Int. J. Mol. Sci. 2015, 16, 28401-28417. [CrossRef] [PubMed] 
154. Eberhardt, R.; Birbamer, G.; Gerstenbrand, F.; Rainer, E.; Traegner, H. Citicoline in the treatment of Parkinson's disease. Clin. Ther. 1990, 12, 489-495. [PubMed]

155. Fioravanti, M.; Yanagi, M. Cytidinediphosphocholine (CDP-choline) for cognitive and behavioural disturbances associated with chronic cerebral disorders in the elderly. Cochrane Database Syst. Rev. 2005. [CrossRef] [PubMed]

156. Chitu, I.; Voinea, L.M.; Istrate, S.; Vrapciu, A.; Ciuluvica, R.C.; Tudosescu, R. The neuroprotective role of citicoline treatment in glaucoma -6 months results of a prospective therapeutic trial. Rom. J. Ophthalmol. 2019, 63, 222-230. [CrossRef]

157. Gandolfi, S.; Marchini, G.; Caporossi, A.; Scuderi, G.; Tomasso, L.; Brunoro, A. Cytidine 5'-Diphosphocholine (Citicoline): Evidence for a Neuroprotective Role in Glaucoma. Nutrients 2020, 12, 793. [CrossRef]

158. Adibhatla, R.M.; Hatcher, J.F. Citicoline mechanisms and clinical efficacy in cerebral ischemia. J. Neurosci. Res. 2002, 70, 133-139. [CrossRef]

159. Martinet, M.; Fonlupt, P.; Pacheco, H. Effects of cytidine- $5^{\prime}$ diphosphocholine on norepinephrine, dopamine and serotonin synthesis in various regions of the rat brain. Arch. Int. Pharmacodyn. Ther. 1979, 239, 52-61.

160. Fioravanti, M.; Buckley, A.E. Citicoline (Cognizin) in the treatment of cognitive impairment. Clin. Interv. Aging 2006, 1, 247-251. [CrossRef]

161. Rejdak, R.; Toczolowski, J.; Solski, J.; Duma, D.; Grieb, P. Citicoline treatment increases retinal dopamine content in rabbits. Ophthalmic Res. 2002, 34, 146-149. [CrossRef]

162. Oshitari, T.; Fujimoto, N.; Adachi-Usami, E. Citicoline has a protective effect on damaged retinal ganglion cells in mouse culture retina. Neuroreport 2002, 13, 2109-2111. [CrossRef] [PubMed]

163. Schuettauf, F.; Rejdak, R.; Thaler, S.; Bolz, S.; Lehaci, C.; Mankowska, A.; Zarnowski, T.; Junemann, A.; Zagorski, Z.; Zrenner, E.; et al. Citicoline and lithium rescue retinal ganglion cells following partial optic nerve crush in the rat. Exp. Eye Res. 2006, 83, 1128-1134. [CrossRef] [PubMed]

164. Matteucci, A.; Varano, M.; Gaddini, L.; Mallozzi, C.; Villa, M.; Pricci, F.; Malchiodi-Albedi, F. Neuroprotective effects of citicoline in in vitro models of retinal neurodegeneration. Int. J. Mol. Sci. 2014, 15, 6286-6297. [CrossRef] [PubMed]

165. Han, Y.S.; Chung, I.Y.; Park, J.M.; Yu, J.M. Neuroprotective effect of citicoline on retinal cell damage induced by kainic acid in rats. Korean J. Ophthalmol. 2005, 19, 219-226. [CrossRef]

166. Park, C.H.; Kim, Y.S.; Cheon, E.W.; Noh, H.S.; Cho, C.H.; Chung, I.Y.; Yoo, J.M.; Kang, S.S.; Choi, W.S.; Cho, G.J. Action of citicoline on rat retinal expression of extracellular-signal-regulated kinase (ERK1/2). Brain Res. 2006, 1081, 203-210. [CrossRef]

167. Park, C.H.; Kim, Y.S.; Lee, H.K.; Kim, Y.H.; Choi, M.Y.; Jung, D.E.; Yoo, J.M.; Kang, S.S.; Choi, W.S.; Cho, G.J. Citicoline reduces upregulated clusterin following kainic acid injection in the rat retina. Curr. Eye Res. 2007, 32, 1055-1063. [CrossRef]

168. Parisi, V.; Coppola, G.; Centofanti, M.; Oddone, F.; Angrisani, A.M.; Ziccardi, L.; Ricci, B.; Quaranta, L.; Manni, G. Evidence of the neuroprotective role of citicoline in glaucoma patients. Prog. Brain Res. 2008, 173, 541-554. [CrossRef]

169. Parisi, V. Electrophysiological assessment of glaucomatous visual dysfunction during treatment with cytidine-5'-diphosphocholine (citicoline): A study of 8 years of follow-up. Doc. Ophthalmol. 2005, 110, 91-102. [CrossRef]

170. Ottobelli, L.; Manni, G.L.; Centofanti, M.; Iester, M.; Allevena, F.; Rossetti, L. Citicoline oral solution in glaucoma: Is there a role in slowing disease progression? Ophthalmologica 2013, 229, 219-226. [CrossRef]

171. Parisi, V.; Centofanti, M.; Ziccardi, L.; Tanga, L.; Michelessi, M.; Roberti, G.; Manni, G. Treatment with citicoline eye drops enhances retinal function and neural conduction along the visual pathways in open angle glaucoma. Graefes Arch. Clin. Exp. Ophthalmol. 2015, 253, 1327-1340. [CrossRef]

172. Rossetti, L.; Iester, M.; Tranchina, L.; Ottobelli, L.; Coco, G.; Calcatelli, E.; Ancona, C.; Cirafici, P.; Manni, G. Can Treatment with Citicoline Eyedrops Reduce Progression in Glaucoma? The Results of a Randomized Placebo-controlled Clinical Trial. J. Glaucoma 2020, 29, 513-520. [CrossRef]

173. Lenaz, G.; Fato, R.; Formiggini, G.; Genova, M.L. The role of Coenzyme Q in mitochondrial electron transport. Mitochondrion 2007, 7, S8-S33. [CrossRef] [PubMed]

174. Crane, F.L. Biochemical functions of coenzyme Q10. J. Am. Coll. Nutr. 2001, 20, 591-598. [CrossRef] 
175. Pinazo-Duran, M.D.; Shoaie-Nia, K.; Zanon-Moreno, V.; Sanz-Gonzalez, S.M.; Del Castillo, J.B.; Garcia-Medina, J.J. Strategies to Reduce Oxidative Stress in Glaucoma Patients. Curr. Neuropharmacol. 2018, 16, 903-918. [CrossRef] [PubMed]

176. Zhang, X.; Tohari, A.M.; Marcheggiani, F.; Zhou, X.; Reilly, J.; Tiano, L.; Shu, X. Therapeutic Potential of Co-enzyme Q10 in Retinal Diseases. Curr. Med. Chem. 2017, 24, 4329-4339. [CrossRef] [PubMed]

177. Nucci, C.; Tartaglione, R.; Cerulli, A.; Mancino, R.; Spano, A.; Cavaliere, F.; Rombola, L.; Bagetta, G.; Corasaniti, M.T.; Morrone, L.A. Retinal damage caused by high intraocular pressure-induced transient ischemia is prevented by coenzyme Q10 in rat. Int. Rev. Neurobiol. 2007, 82, 397-406. [CrossRef]

178. Russo, R.; Cavaliere, F.; Rombola, L.; Gliozzi, M.; Cerulli, A.; Nucci, C.; Fazzi, E.; Bagetta, G.; Corasaniti, M.T.; Morrone, L.A. Rational basis for the development of coenzyme Q10 as a neurotherapeutic agent for retinal protection. Prog. Brain Res. 2008, 173, 575-582. [CrossRef]

179. Papucci, L.; Schiavone, N.; Witort, E.; Donnini, M.; Lapucci, A.; Tempestini, A.; Formigli, L.; Zecchi-Orlandini, S.; Orlandini, G.; Carella, G.; et al. Coenzyme q10 prevents apoptosis by inhibiting mitochondrial depolarization independently of its free radical scavenging property. J. Biol. Chem. 2003, 278, 28220-28228. [CrossRef] [PubMed]

180. Ju, W.K.; Shim, M.S.; Kim, K.Y.; Bu, J.H.; Park, T.L.; Ahn, S.; Weinreb, R.N. Ubiquinol promotes retinal ganglion cell survival and blocks the apoptotic pathway in ischemic retinal degeneration. Biochem. Biophys. Res. Commun. 2018, 503, 2639-2645. [CrossRef]

181. Lee, D.; Kim, K.Y.; Shim, M.S.; Kim, S.Y.; Ellisman, M.H.; Weinreb, R.N.; Ju, W.K. Coenzyme Q10 ameliorates oxidative stress and prevents mitochondrial alteration in ischemic retinal injury. Apoptosis 2014, 19, 603-614. [CrossRef]

182. Noh, Y.H.; Kim, K.Y.; Shim, M.S.; Choi, S.H.; Choi, S.; Ellisman, M.H.; Weinreb, R.N.; Perkins, G.A.; Ju, W.K. Inhibition of oxidative stress by coenzyme Q10 increases mitochondrial mass and improves bioenergetic function in optic nerve head astrocytes. Cell Death Dis. 2013, 4, e820. [CrossRef] [PubMed]

183. Bhagavan, H.N.; Chopra, R.K. Coenzyme Q10: Absorption, tissue uptake, metabolism and pharmacokinetics. Free Radic. Res. 2006, 40, 445-453. [CrossRef] [PubMed]

184. Davis, B.M.; Tian, K.; Pahlitzsch, M.; Brenton, J.; Ravindran, N.; Butt, G.; Malaguarnera, G.; Normando, E.M.; Guo, L.; Cordeiro, M.F. Topical Coenzyme Q10 demonstrates mitochondrial-mediated neuroprotection in a rodent model of ocular hypertension. Mitochondrion 2017, 36, 114-123. [CrossRef]

185. Itagaki, S.; Ochiai, A.; Kobayashi, M.; Sugawara, M.; Hirano, T.; Iseki, K. Interaction of coenzyme Q10 with the intestinal drug transporter P-glycoprotein. J. Agric. Food Chem. 2008, 56, 6923-6927. [CrossRef] [PubMed]

186. Ekicier Acar, S.; Saricaoglu, M.S.; Colak, A.; Aktas, Z.; Sepici Dincel, A. Neuroprotective effects of topical coenzyme Q10 + vitamin E in mechanic optic nerve injury model. Eur. J. Ophthalmol. 2020, 30, 714-722. [CrossRef]

187. Ozates, S.; Elgin, K.U.; Yilmaz, N.S.; Demirel, O.O.; Sen, E.; Yilmazbas, P. Evaluation of oxidative stress in pseudo-exfoliative glaucoma patients treated with and without topical coenzyme Q10 and vitamin E. Eur. J. Ophthalmol. 2019, 29, 196-201. [CrossRef] [PubMed]

188. Parisi, V.; Centofanti, M.; Gandolfi, S.; Marangoni, D.; Rossetti, L.; Tanga, L.; Tardini, M.; Traina, S.; Ungaro, N.; Vetrugno, M.; et al. Effects of coenzyme Q10 in conjunction with vitamin E on retinal-evoked and cortical-evoked responses in patients with open-angle glaucoma. J. Glaucoma 2014, 23, 391-404. [CrossRef]

189. Quaranta, L.; Riva, I.; Biagioli, E.; Rulli, E.; Rulli, E.; Poli, D.; Legramandi, L.; CoQun Study Group. Evaluating the Effects of an Ophthalmic Solution of Coenzyme Q10 and Vitamin E in Open-Angle Glaucoma Patients: A Study Protocol. Adv. Ther. 2019, 36, 2506-2514. [CrossRef]

190. Froger, N.; Moutsimilli, L.; Cadetti, L.; Jammoul, F.; Wang, Q.P.; Fan, Y.; Gaucher, D.; Rosolen, S.G.; Neveux, N.; Cynober, L.; et al. Taurine: The comeback of a neutraceutical in the prevention of retinal degenerations. Prog. Retin. Eye Res. 2014, 41, 44-63. [CrossRef] [PubMed]

191. Tornquist, P.; Alm, A. Carrier-mediated transport of amino acids through the blood-retinal and the blood-brain barriers. Graefes Arch. Clin. Exp. 1986, 224, 21-25. [CrossRef]

192. Voaden, M.J.; Lake, N.; Marshall, J.; Morjaria, B. Studies on the distribution of taurine and other neuroactive amino acids in the retina. Exp. Eye Res. 1977, 25, 249-257. [CrossRef]

193. Hayes, K.C.; Carey, R.E.; Schmidt, S.Y. Retinal degeneration associated with taurine deficiency in the cat. Science 1975, 188, 949-951. [CrossRef] [PubMed] 
194. Neuringer, M.; Sturman, J. Visual acuity loss in rhesus monkey infants fed a taurine-free human infant formula. J. Neurosci. Res. 1987, 18, 597-601. [CrossRef] [PubMed]

195. Madl, J.E.; McIlnay, T.R.; Powell, C.C.; Gionfriddo, J.R. Depletion of taurine and glutamate from damaged photoreceptors in the retinas of dogs with primary glaucoma. Am. J. Vet. Res. 2005, 66, 791-799. [CrossRef]

196. Jammoul, F.; Wang, Q.; Nabbout, R.; Coriat, C.; Duboc, A.; Simonutti, M.; Dubus, E.; Craft, C.M.; Ye, W.; Collins, S.D.; et al. Taurine deficiency is a cause of vigabatrin-induced retinal phototoxicity. Ann. Neurol. 2009, 65, 98-107. [CrossRef]

197. Garcia-Ayuso, D.; Di Pierdomenico, J.; Hadj-Said, W.; Marie, M.; Agudo-Barriuso, M.; Vidal-Sanz, M.; Picaud, S.; Villegas-Perez, M.P. Taurine Depletion Causes ipRGC Loss and Increases Light-Induced Photoreceptor Degeneration. Investig. Ophthalmol. Vis. Sci. 2018, 59, 1396-1409. [CrossRef]

198. Garcia-Ayuso, D.; Di Pierdomenico, J.; Valiente-Soriano, F.J.; Martinez-Vacas, A.; Agudo-Barriuso, M.; Vidal-Sanz, M.; Picaud, S.; Villegas-Perez, M.P. Beta-alanine supplementation induces taurine depletion and causes alterations of the retinal nerve fiber layer and axonal transport by retinal ganglion cells. Exp. Eye Res. 2019, 188, 107781. [CrossRef]

199. Buisset, A.; Gohier, P.; Leruez, S.; Muller, J.; Amati-Bonneau, P.; Lenaers, G.; Bonneau, D.; Simard, G.; Procaccio, V.; Annweiler, C.; et al. Metabolomic Profiling of Aqueous Humor in Glaucoma Points to Taurine and Spermine Deficiency: Findings from the Eye-D Study. J. Proteome Res. 2019, 18, 1307-1315. [CrossRef]

200. Froger, N.; Cadetti, L.; Lorach, H.; Martins, J.; Bemelmans, A.P.; Dubus, E.; Degardin, J.; Pain, D.; Forster, V.; Chicaud, L.; et al. Taurine provides neuroprotection against retinal ganglion cell degeneration. PLoS ONE 2012, 7, e42017. [CrossRef]

201. Lambuk, L.; Jafri, A.J.; Arfuzir, N.N.; Iezhitsa, I.; Agarwal, R.; Rozali, K.N.; Agarwal, P.; Bakar, N.S.; Kutty, M.K.; Yusof, A.P.; et al. Neuroprotective Effect of Magnesium Acetyltaurate against NMDA-Induced Excitotoxicity in Rat Retina. Neurotox. Res. 2017, 31, 31-45. [CrossRef]

202. Jafri, A.J.A.; Agarwal, R.; Iezhitsa, I.; Agarwal, P.; Spasov, A.; Ozerov, A.; Ismail, N.M. Protective effect of magnesium acetyltaurate and taurine against NMDA-induced retinal damage involves reduced nitrosative stress. Mol. Vis. 2018, 24, 495-508. [PubMed]

203. Lambuk, L.; Iezhitsa, I.; Agarwal, R.; Bakar, N.S.; Agarwal, P.; Ismail, N.M. Antiapoptotic effect of taurine against NMDA-induced retinal excitotoxicity in rats. Neurotoxicology 2019, 70, 62-71. [CrossRef] [PubMed]

204. Han, Z.; Gao, L.Y.; Lin, Y.H.; Chang, L.; Wu, H.Y.; Luo, C.X.; Zhu, D.Y. Neuroprotection of taurine against reactive oxygen species is associated with inhibiting NADPH oxidases. Eur. J. Pharmacol. 2016, 777, 129-135. [CrossRef] [PubMed]

205. Hadj-Said, W.; Fradot, V.; Ivkovic, I.; Sahel, J.A.; Picaud, S.; Froger, N. Taurine Promotes Retinal Ganglion Cell Survival through GABAB Receptor Activation. Adv. Exp. Med. Biol. 2017, 975, 687-701. [CrossRef] [PubMed]

206. Peterson, J.; Dwyer, J. Taxonomic classification helps identify flavonoid-containing foods on a semiquantitative food frequency questionnaire. J. Am. Diet. Assoc. 1998, 98, 677-685. [CrossRef]

207. Ross, J.A.; Kasum, C.M. Dietary flavonoids: Bioavailability, metabolic effects, and safety. Annu. Rev. Nutr. 2002, 22, 19-34. [CrossRef] [PubMed]

208. Middleton, E., Jr.; Kandaswami, C.; Theoharides, T.C. The effects of plant flavonoids on mammalian cells: Implications for inflammation, heart disease, and cancer. Pharmacol. Rev. 2000, 52, 673-751. [PubMed]

209. Patel, S.; Mathan, J.J.; Vaghefi, E.; Braakhuis, A.J. The effect of flavonoids on visual function in patients with glaucoma or ocular hypertension: A systematic review and meta-analysis. Graefes Arch. Clin. Exp. Ophthalmol. 2015, 253, 1841-1850. [CrossRef]

210. Loskutova, E.; O’Brien, C.; Loskutov, I.; Loughman, J. Nutritional supplementation in the treatment of glaucoma: A systematic review. Surv. Ophthalmol. 2019, 64, 195-216. [CrossRef]

211. Birks, J.; Evans, J.G. Ginkgo biloba for cognitive impairment and dementia. Cochrane Database Syst. Rev. 2009. [CrossRef]

212. Kang, J.M.; Lin, S. Ginkgo biloba and its potential role in glaucoma. Curr. Opin. Ophthalmol. 2018, 29, 116-120. [CrossRef] [PubMed]

213. Hirooka, K.; Tokuda, M.; Miyamoto, O.; Itano, T.; Baba, T.; Shiraga, F. The Ginkgo biloba extract (EGb 761) provides a neuroprotective effect on retinal ganglion cells in a rat model of chronic glaucoma. Curr. Eye Res. 2004, 28, 153-157. [CrossRef] [PubMed] 
214. Cho, H.K.; Kim, S.; Lee, E.J.; Kee, C. Neuroprotective Effect of Ginkgo Biloba Extract against Hypoxic Retinal Ganglion Cell Degeneration In Vitro and In Vivo. J. Med. Food 2019, 22, 771-778. [CrossRef] [PubMed]

215. Ma, K.; Xu, L.; Zhang, H.; Zhang, S.; Pu, M.; Jonas, J.B. The effect of ginkgo biloba on the rat retinal ganglion cell survival in the optic nerve crush model. Acta Ophthalmol. 2010, 88, 553-557. [CrossRef]

216. Ma, K.; Xu, L.; Zhan, H.; Zhang, S.; Pu, M.; Jonas, J.B. Dosage dependence of the effect of Ginkgo biloba on the rat retinal ganglion cell survival after optic nerve crush. Eye 2009, 23, 1598-1604. [CrossRef]

217. Park, J.W.; Kwon, H.J.; Chung, W.S.; Kim, C.Y.; Seong, G.J. Short-term effects of Ginkgo biloba extract on peripapillary retinal blood flow in normal tension glaucoma. Korean J. Ophthalmol. 2011, 25, 323-328. [CrossRef]

218. Harris, A.; Gross, J.; Moore, N.; Do, T.; Huang, A.; Gama, W.; Siesky, B. The effects of antioxidants on ocular blood flow in patients with glaucoma. Acta Ophthalmol. 2018, 96, e237-e241. [CrossRef]

219. Quaranta, L.; Bettelli, S.; Uva, M.G.; Semeraro, F.; Turano, R.; Gandolfo, E. Effect of Ginkgo biloba extract on preexisting visual field damage in normal tension glaucoma. Ophthalmology 2003, 110, 359-362. [CrossRef]

220. Shim, S.H.; Kim, J.M.; Choi, C.Y.; Kim, C.Y.; Park, K.H. Ginkgo biloba extract and bilberry anthocyanins improve visual function in patients with normal tension glaucoma. J. Med. Food 2012, 15, 818-823. [CrossRef]

221. Guo, X.; He, M.; Patel, M.; Congdon, N.G. Author response: Ginkgo biloba extract improves visual field damage in some patients affected by normal-tension glaucoma. Investig. Ophthalmol. Vis. Sci. 2014, 55, 2418. [CrossRef]

222. Khan, N.; Mukhtar, H. Tea Polyphenols in Promotion of Human Health. Nutrients 2018, 11, 39. [CrossRef] [PubMed]

223. Falsini, B.; Marangoni, D.; Salgarello, T.; Stifano, G.; Montrone, L.; Di Landro, S.; Guccione, L.; Balestrazzi, E.; Colotto, A. Effect of epigallocatechin-gallate on inner retinal function in ocular hypertension and glaucoma: A short-term study by pattern electroretinogram. Graefes Arch. Clin. Exp. Ophthalmol. 2009, 247, 1223-1233. [CrossRef] [PubMed]

224. Zhang, B.; Safa, R.; Rusciano, D.; Osborne, N.N. Epigallocatechin gallate, an active ingredient from green tea, attenuates damaging influences to the retina caused by ischemia/reperfusion. Brain Res. 2007, 1159, 40-53. [CrossRef] [PubMed]

225. Xie, J.; Jiang, L.; Zhang, T.; Jin, Y.; Yang, D.; Chen, F. Neuroprotective effects of Epigallocatechin-3-gallate (EGCG) in optic nerve crush model in rats. Neurosci. Lett. 2010, 479, 26-30. [CrossRef]

226. Peng, P.H.; Ko, M.L.; Chen, C.F. Epigallocatechin-3-gallate reduces retinal ischemia/reperfusion injury by attenuating neuronal nitric oxide synthase expression and activity. Exp. Eye Res. 2008, 86, 637-646. [CrossRef]

227. Peng, P.H.; Chiou, L.F.; Chao, H.M.; Lin, S.; Chen, C.F.; Liu, J.H.; Ko, M.L. Effects of epigallocatechin-3-gallate on rat retinal ganglion cells after optic nerve axotomy. Exp. Eye Res. 2010, 90, 528-534. [CrossRef]

228. Chu, K.O.; Chan, K.P.; Yang, Y.P.; Qin, Y.J.; Li, W.Y.; Chan, S.O.; Wang, C.C.; Pang, C.P. Effects of EGCG content in green tea extract on pharmacokinetics, oxidative status and expression of inflammatory and apoptotic genes in the rat ocular tissues. J. Nutr. Biochem. 2015, 26, 1357-1367. [CrossRef]

229. Yang, Y.; Xu, C.; Chen, Y.; Liang, J.J.; Xu, Y.; Chen, S.L.; Huang, S.; Yang, Q.; Cen, L.P.; Pang, C.P.; et al. Green Tea Extract Ameliorates Ischemia-Induced Retinal Ganglion Cell Degeneration in Rats. Oxidative Med. Cell. Longev. 2019, 2019, 8407206. [CrossRef]

230. Abu-Amero, K.K.; Kondkar, A.A.; Chalam, K.V. Resveratrol and Ophthalmic Diseases. Nutrients 2016, 8, 200. [CrossRef]

231. Zuo, L.; Khan, R.S.; Lee, V.; Dine, K.; Wu, W.; Shindler, K.S. SIRT1 promotes RGC survival and delays loss of function following optic nerve crush. Investig. Ophthalmol. Vis. Sci. 2013, 54, 5097-5102. [CrossRef]

232. Lindsey, J.D.; Duong-Polk, K.X.; Hammond, D.; Leung, C.K.; Weinreb, R.N. Protection of injured retinal ganglion cell dendrites and unfolded protein response resolution after long-term dietary resveratrol. Neurobiol. Aging 2015, 36, 1969-1981. [CrossRef] [PubMed]

233. Zhang, X.; Feng, Y.; Wang, Y.; Wang, J.; Xiang, D.; Niu, W.; Yuan, F. Resveratrol ameliorates disorders of mitochondrial biogenesis and dynamics in a rat chronic ocular hypertension model. Life Sci. 2018, 207, 234-245. [CrossRef] [PubMed]

234. Seong, H.; Ryu, J.; Yoo, W.S.; Kim, S.J.; Han, Y.S.; Park, J.M.; Kang, S.S.; Seo, S.W. Resveratrol Ameliorates Retinal Ischemia/Reperfusion Injury in C57BL/6J Mice via Downregulation of Caspase-3. Curr. Eye Res. 2017, 42, 1650-1658. [CrossRef] 
235. Luo, H.; Zhuang, J.; Hu, P.; Ye, W.; Chen, S.; Pang, Y.; Li, N.; Deng, C.; Zhang, X. Resveratrol Delays Retinal Ganglion Cell Loss and Attenuates Gliosis-Related Inflammation from Ischemia-Reperfusion Injury. Investig. Ophthalmol. Vis. Sci. 2018, 59, 3879-3888. [CrossRef]

236. Cao, K.; Ishida, T.; Fang, Y.; Shinohara, K.; Li, X.; Nagaoka, N.; Ohno-Matsui, K.; Yoshida, T. Protection of the Retinal Ganglion Cells: Intravitreal Injection of Resveratrol in Mouse Model of Ocular Hypertension. Investig. Ophthalmol. Vis. Sci. 2020, 61, 13. [CrossRef] [PubMed]

237. Liu, S.Y.; Song, J.Y.; Fan, B.; Wang, Y.; Pan, Y.R.; Che, L.; Sun, Y.J.; Li, G.Y. Resveratrol protects photoreceptors by blocking caspase- and PARP-dependent cell death pathways. Free Radic. Biol. Med. 2018, 129, 569-581. [CrossRef]

238. Luna, C.; Li, G.; Liton, P.B.; Qiu, J.; Epstein, D.L.; Challa, P.; Gonzalez, P. Resveratrol prevents the expression of glaucoma markers induced by chronic oxidative stress in trabecular meshwork cells. Food Chem. Toxicol. 2009, 47, 198-204. [CrossRef]

239. Avotri, S.; Eatman, D.; Russell-Randall, K. Effects of Resveratrol on Inflammatory Biomarkers in Glaucomatous Human Trabecular Meshwork Cells. Nutrients 2019, 11, 984. [CrossRef]

240. Deng, C.; Chen, S.; Li, X.; Luo, H.; Zhang, Q.; Hu, P.; Wang, F.; Xiong, C.; Sun, T.; Zhang, X. Role of the PGE2 receptor in ischemia-reperfusion injury of the rat retina. Mol. Vis. 2020, 26, 36-47.

241. Sapio, L.; Gallo, M.; Illiano, M.; Chiosi, E.; Naviglio, D.; Spina, A.; Naviglio, S. The Natural cAMP Elevating Compound Forskolin in Cancer Therapy: Is It Time? J. Cell. Physiol. 2017, 232, 922-927. [CrossRef]

242. Caprioli, J.; Sears, M. Forskolin lowers intraocular pressure in rabbits, monkeys, and man. Lancet 1983, 1, 958-960. [CrossRef]

243. Caprioli, J.; Sears, M.; Bausher, L.; Gregory, D.; Mead, A. Forskolin lowers intraocular pressure by reducing aqueous inflow. Investig. Ophthalmol. Vis. Sci. 1984, 25, 268-277.

244. Zeng, S.; Shen, B.; Wen, L.; Hu, B.; Peng, D.; Chen, X.; Zhou, W. Experimental studies of the effect of Forskolin on the lowering of intraocular pressure. Yan Ke Xue Bao 1995, 11, 173-176. [PubMed]

245. Burstein, N.L.; Sears, M.L.; Mead, A. Aqueous flow in human eyes is reduced by forskolin, a potent adenylate cyclase activator. Exp. Eye Res. 1984, 39, 745-749. [CrossRef]

246. Wagh, V.D.; Patil, P.N.; Surana, S.J.; Wagh, K.V. Forskolin: Upcoming antiglaucoma molecule. J. Postgrad. Med. 2012, 58, 199-202. [CrossRef]

247. Pescosolido, N.; Librando, A. Oral administration of an association of forskolin, rutin and vitamins B1 and B2 potentiates the hypotonising effects of pharmacological treatments in POAG patients. Clin. Ter. 2010, 161, e81-e85. [PubMed]

248. Vetrugno, M.; Uva, M.G.; Russo, V.; Iester, M.; Ciancaglini, M.; Brusini, P.; Centofanti, M.; Rossetti, L.M. Oral administration of forskolin and rutin contributes to intraocular pressure control in primary open angle glaucoma patients under maximum tolerated medical therapy. J. Ocul. Pharmacol. Ther. 2012, 28, 536-541. [CrossRef]

249. Mutolo, M.G.; Albanese, G.; Rusciano, D.; Pescosolido, N. Oral Administration of Forskolin, Homotaurine, Carnosine, and Folic Acid in Patients with Primary Open Angle Glaucoma: Changes in Intraocular Pressure, Pattern Electroretinogram Amplitude, and Foveal Sensitivity. J. Ocul. Pharmacol. Ther. 2016, 32, 178-183. [CrossRef]

250. Watanabe, M.; Tokita, Y.; Kato, M.; Fukuda, Y. Intravitreal injections of neurotrophic factors and forskolin enhance survival and axonal regeneration of axotomized beta ganglion cells in cat retina. Neuroscience 2003, 116, 733-742. [CrossRef]

251. Meyer-Franke, A.; Kaplan, M.R.; Pfrieger, F.W.; Barres, B.A. Characterization of the signaling interactions that promote the survival and growth of developing retinal ganglion cells in culture. Neuron 1995, 15, 805-819. [CrossRef]

252. Shen, S.; Wiemelt, A.P.; McMorris, F.A.; Barres, B.A. Retinal ganglion cells lose trophic responsiveness after axotomy. Neuron 1999, 23, 285-295. [CrossRef]

253. Watanabe, M.; Fukuda, Y. Survival and axonal regeneration of retinal ganglion cells in adult cats. Prog. Retin. Eye Res. 2002, 21, 529-553. [CrossRef]

254. Russo, R.; Adornetto, A.; Cavaliere, F.; Varano, G.P.; Rusciano, D.; Morrone, L.A.; Corasaniti, M.T.; Bagetta, G.; Nucci, C. Intravitreal injection of forskolin, homotaurine, and L-carnosine affords neuroprotection to retinal ganglion cells following retinal ischemic injury. Mol. Vis. 2015, 21, 718-729. [PubMed] 
255. Locri, F.; Cammalleri, M.; Dal Monte, M.; Rusciano, D.; Bagnoli, P. Protective Efficacy of a Dietary Supplement Based on Forskolin, Homotaurine, Spearmint Extract, and Group B Vitamins in a Mouse Model of Optic Nerve Injury. Nutrients 2019, 11, 2931. [CrossRef]

256. Cammalleri, M.; Dal Monte, M.; Amato, R.; Bagnoli, P.; Rusciano, D. A Dietary Combination of Forskolin with Homotaurine, Spearmint and B Vitamins Protects Injured Retinal Ganglion Cells in a Rodent Model of Hypertensive Glaucoma. Nutrients 2020, 12, 1189. [CrossRef]

257. Prasad, S.; Aggarwal, B.B. Turmeric, the Golden Spice: From Traditional Medicine to Modern Medicine. In Herbal Medicine: Biomolecular and Clinical Aspects, 2nd ed.; Benzie, I.F.F., Wachtel-Galor, S., Eds.; CRC Press/Taylor \& Francis: Boca Raton, FL, USA, 2011.

258. Tai, Y.H.; Lin, Y.Y.; Wang, K.C.; Chang, C.L.; Chen, R.Y.; Wu, C.C.; Cheng, I.H. Curcuminoid submicron particle ameliorates cognitive deficits and decreases amyloid pathology in Alzheimer's disease mouse model. Oncotarget 2018, 9, 10681-10697. [CrossRef]

259. Wang, Q.; Sun, A.Y.; Simonyi, A.; Jensen, M.D.; Shelat, P.B.; Rottinghaus, G.E.; MacDonald, R.S.; Miller, D.K.; Lubahn, D.E.; Weisman, G.A.; et al. Neuroprotective mechanisms of curcumin against cerebral ischemia-induced neuronal apoptosis and behavioral deficits. J. Neurosci. Res. 2005, 82, 138-148. [CrossRef]

260. Wang, R.; Li, Y.B.; Li, Y.H.; Xu, Y.; Wu, H.L.; Li, X.J. Curcumin protects against glutamate excitotoxicity in rat cerebral cortical neurons by increasing brain-derived neurotrophic factor level and activating TrkB. Brain Res. 2008, 1210, 84-91. [CrossRef]

261. Davis, B.M.; Pahlitzsch, M.; Guo, L.; Balendra, S.; Shah, P.; Ravindran, N.; Malaguarnera, G.; Sisa, C.; Shamsher, E.; Hamze, H.; et al. Topical Curcumin Nanocarriers are Neuroprotective in Eye Disease. Sci. Rep. 2018, 8, 11066. [CrossRef]

262. Hussain, Z.; Thu, H.E.; Amjad, M.W.; Hussain, F.; Ahmed, T.A.; Khan, S. Exploring recent developments to improve antioxidant, anti-inflammatory and antimicrobial efficacy of curcumin: A review of new trends and future perspectives. Mater. Sci. Eng. C Mater. Biol. Appl. 2017, 77, 1316-1326. [CrossRef] [PubMed]

263. Jat, D.; Parihar, P.; Kothari, S.C.; Parihar, M.S. Curcumin reduces oxidative damage by increasing reduced glutathione and preventing membrane permeability transition in isolated brain mitochondria. Cell. Mol. Biol. (Noisy-le-grand) 2013, 59, OL1899-OL1905.

264. Suryanarayana, P.; Saraswat, M.; Mrudula, T.; Krishna, T.P.; Krishnaswamy, K.; Reddy, G.B. Curcumin and turmeric delay streptozotocin-induced diabetic cataract in rats. Investig. Ophthalmol. Vis. Sci. 2005, 46, 2092-2099. [CrossRef]

265. Trujillo, J.; Granados-Castro, L.F.; Zazueta, C.; Anderica-Romero, A.C.; Chirino, Y.I.; Pedraza-Chaverri, J. Mitochondria as a target in the therapeutic properties of curcumin. Arch. Pharm. 2014, 347, 873-884. [CrossRef] [PubMed]

266. Liu, S.; Li, Q.; Zhang, M.T.; Mao-Ying, Q.L.; Hu, L.Y.; Wu, G.C.; Mi, W.L.; Wang, Y.Q. Curcumin ameliorates neuropathic pain by down-regulating spinal IL-1beta via suppressing astroglial NALP1 inflammasome and JAK2-STAT3 signalling. Sci. Rep. 2016, 6, 28956. [CrossRef] [PubMed]

267. Gao, J.Z.; Du, J.L.; Wang, Y.L.; Li, J.; Wei, L.X.; Guo, M.Z. Synergistic effects of curcumin and bevacizumab on cell signaling pathways in hepatocellular carcinoma. Oncol. Lett. 2015, 9, 295-299. [CrossRef] [PubMed]

268. Gonzales, A.M.; Orlando, R.A. Curcumin and resveratrol inhibit nuclear factor-kappaB-mediated cytokine expression in adipocytes. Nutr. Metab. 2008, 5, 17. [CrossRef]

269. Olivera, A.; Moore, T.W.; Hu, F.; Brown, A.P.; Sun, A.; Liotta, D.C.; Snyder, J.P.; Yoon, Y.; Shim, H.; Marcus, A.I.; et al. Inhibition of the NF-kappaB signaling pathway by the curcumin analog, 3,5-Bis(2-pyridinylmethylidene)-4-piperidone (EF31): Anti-inflammatory and anti-cancer properties. Int. Immunopharmacol. 2012, 12, 368-377. [CrossRef]

270. $\mathrm{Xu}, \mathrm{J} . ; \mathrm{Fu}, \mathrm{Y}$; Chen, A. Activation of peroxisome proliferator-activated receptor-gamma contributes to the inhibitory effects of curcumin on rat hepatic stellate cell growth. Am. J. Physiol. Gastrointest. Liver Physiol. 2003, 285, G20-G30. [CrossRef]

271. Esmaily, H.; Sahebkar, A.; Iranshahi, M.; Ganjali, S.; Mohammadi, A.; Ferns, G.; Ghayour-Mobarhan, M. An investigation of the effects of curcumin on anxiety and depression in obese individuals: A randomized controlled trial. Chin. J. Integr. Med. 2015, 21, 332-338. [CrossRef] 
272. Matteucci, A.; Frank, C.; Domenici, M.R.; Balduzzi, M.; Paradisi, S.; Carnovale-Scalzo, G.; Scorcia, G.; Malchiodi-Albedi, F. Curcumin treatment protects rat retinal neurons against excitotoxicity: Effect on N-methyl-D: -aspartate-induced intracellular Ca(2+) increase. Exp. Brain Res. 2005, 167, 641-648. [CrossRef]

273. Matteucci, A.; Cammarota, R.; Paradisi, S.; Varano, M.; Balduzzi, M.; Leo, L.; Bellenchi, G.C.; De Nuccio, C.; Carnovale-Scalzo, G.; Scorcia, G.; et al. Curcumin protects against NMDA-induced toxicity: A possible role for NR2A subunit. Investig. Ophthalmol. Vis. Sci. 2011, 52, 1070-1077. [CrossRef]

274. Wang, L.; Li, C.; Guo, H.; Kern, T.S.; Huang, K.; Zheng, L. Curcumin inhibits neuronal and vascular degeneration in retina after ischemia and reperfusion injury. PLoS ONE 2011, 6, e23194. [CrossRef] [PubMed]

275. Yue, Y.K.; Mo, B.; Zhao, J.; Yu, Y.J.; Liu, L.; Yue, C.L.; Liu, W. Neuroprotective effect of curcumin against oxidative damage in BV-2 microglia and high intraocular pressure animal model. J. Ocul. Pharmacol. Ther. 2014, 30, 657-664. [CrossRef] [PubMed]

276. Sharma, R.A.; Euden, S.A.; Platton, S.L.; Cooke, D.N.; Shafayat, A.; Hewitt, H.R.; Marczylo, T.H.; Morgan, B.; Hemingway, D.; Plummer, S.M.; et al. Phase I clinical trial of oral curcumin: Biomarkers of systemic activity and compliance. Clin. Cancer Res. 2004, 10, 6847-6854. [CrossRef] [PubMed]

277. Gupta, S.C.; Patchva, S.; Aggarwal, B.B. Therapeutic roles of curcumin: Lessons learned from clinical trials. AAPS J. 2013, 15, 195-218. [CrossRef] [PubMed]

278. Cheng, Y.H.; Ko, Y.C.; Chang, Y.F.; Huang, S.H.; Liu, C.J. Thermosensitive chitosan-gelatin-based hydrogel containing curcumin-loaded nanoparticles and latanoprost as a dual-drug delivery system for glaucoma treatment. Exp. Eye Res. 2019, 179, 179-187. [CrossRef] [PubMed]

279. Lin, C.; Wu, X. Curcumin Protects Trabecular Meshwork Cells from Oxidative Stress. Investig. Ophthalmol. Vis. Sci. 2016, 57, 4327-4332. [CrossRef]

280. Gao, Y.; Wei, Y.; Wang, Y.; Gao, F.; Chen, Z. Lycium Barbarum: A Traditional Chinese Herb and A Promising Anti-Aging Agent. Aging Dis. 2017, 8, 778-791. [CrossRef]

281. Gan, L.; Zhang, S.H.; Yang, X.L.; Xu, H.B. Immunomodulation and antitumor activity by a polysaccharide-protein complex from Lycium barbarum. Int. Immunopharmacol. 2004, 4, 563-569. [CrossRef]

282. Manthey, A.L.; Chiu, K.; So, K.F. Effects of Lycium barbarum on the Visual System. Int. Rev. Neurobiol. 2017, 135, 1-27. [CrossRef]

283. Huang, L.; Lin, Y.; Tian, G.; Ji, G. Isolation, purification and physico-chemical properties of immunoactive constituents from the fruit of Lycium barbarum L. Yao Xие Xие Bao 1998, 33, 512-516.

284. Xing, X.; Liu, F.; Xiao, J.; So, K.F. Neuro-protective Mechanisms of Lycium barbarum. Neuromol. Med. 2016, 18, 253-263. [CrossRef] [PubMed]

285. Li, X.M.; Ma, Y.L.; Liu, X.J. Effect of the Lycium barbarum polysaccharides on age-related oxidative stress in aged mice. J. Ethnopharmacol. 2007, 111, 504-511. [CrossRef] [PubMed]

286. Mi, X.S.; Feng, Q.; Lo, A.C.; Chang, R.C.; Lin, B.; Chung, S.K.; So, K.F. Protection of retinal ganglion cells and retinal vasculature by Lycium barbarum polysaccharides in a mouse model of acute ocular hypertension. PLOS ONE 2012, 7, e45469. [CrossRef]

287. He, M.; Pan, H.; Chang, R.C.; So, K.F.; Brecha, N.C.; Pu, M. Activation of the Nrf2/HO-1 antioxidant pathway contributes to the protective effects of Lycium barbarum polysaccharides in the rodent retina after ischemia-reperfusion-induced damage. PLoS ONE 2014, 9, e84800. [CrossRef] [PubMed]

288. Chan, H.C.; Chang, R.C.; Ip, A.K.C.; Chiu, K.; Yuen, W.H.; Zee, S.Y.; So, K.F. Neuroprotective effects of Lycium barbarum Lynn on protecting retinal ganglion cells in an ocular hypertension model of glaucoma. Exp. Neurol. 2007, 203, 269-273. [CrossRef] [PubMed]

289. Chiu, K.; Chan, H.C.; Yeung, S.C.; Yuen, W.H.; Zee, S.Y.; Chang, R.C.; So, K.F. Modulation of microglia by Wolfberry on the survival of retinal ganglion cells in a rat ocular hypertension model. J. Ocul. Biol. Dis. Inform. 2009, 2, 47-56. [CrossRef] [PubMed]

290. Chiu, K.; Zhou, Y.; Yeung, S.C.; Lok, C.K.; Chan, O.O.; Chang, R.C.; So, K.F.; Chiu, J.F. Up-regulation of crystallins is involved in the neuroprotective effect of wolfberry on survival of retinal ganglion cells in rat ocular hypertension model. J. Cell. Biochem. 2010, 110, 311-320. [CrossRef]

291. Lakshmanan, Y.; Wong, F.S.Y.; Zuo, B.; So, K.F.; Bui, B.V.; Chan, H.H. Posttreatment Intervention with Lycium Barbarum Polysaccharides is Neuroprotective in a Rat Model of Chronic Ocular Hypertension. Investig. Ophthalmol. Vis. Sci. 2019, 60, 4606-4618. [CrossRef] 
292. Li, H.; Liang, Y.; Chiu, K.; Yuan, Q.; Lin, B.; Chang, R.C.; So, K.F. Lycium barbarum (wolfberry) reduces secondary degeneration and oxidative stress, and inhibits JNK pathway in retina after partial optic nerve transection. PLoS ONE 2013, 8, e68881. [CrossRef]

293. Li, H.Y.; Ruan, Y.W.; Kau, P.W.; Chiu, K.; Chang, R.C.; Chan, H.H.; So, K.F. Effect of Lycium barbarum (Wolfberry) on alleviating axonal degeneration after partial optic nerve transection. Cell Transplant. 2015, 24, 403-417. [CrossRef]

294. Li, H.Y.; Huang, M.; Luo, Q.Y.; Hong, X.; Ramakrishna, S.; So, K.F. Lycium barbarum (Wolfberry) Increases Retinal Ganglion Cell Survival and Affects both Microglia/Macrophage Polarization and Autophagy after Rat Partial Optic Nerve Transection. Cell Transplant. 2019, 28, 607-618. [CrossRef]

295. Chan, H.H.; Lam, H.I.; Choi, K.Y.; Li, S.Z.; Lakshmanan, Y.; Yu, W.Y.; Chang, R.C.; Lai, J.S.; So, K.F. Delay of cone degeneration in retinitis pigmentosa using a 12-month treatment with Lycium barbarum supplement. J. Ethnopharmacol. 2019, 236, 336-344. [CrossRef]

296. Ochiai, T.; Shimeno, H.; Mishima, K.; Iwasaki, K.; Fujiwara, M.; Tanaka, H.; Shoyama, Y.; Toda, A.; Eyanagi, R.; Soeda, S. Protective effects of carotenoids from saffron on neuronal injury in vitro and in vivo. Biochim. Biophys. Acta 2007, 1770, 578-584. [CrossRef]

297. Pitsikas, N. Constituents of Saffron (Crocus sativus L.) as Potential Candidates for the Treatment of Anxiety Disorders and Schizophrenia. Molecules 2016, 21, 303. [CrossRef]

298. Moshiri, M.; Vahabzadeh, M.; Hosseinzadeh, H. Clinical Applications of Saffron (Crocus sativus) and its Constituents: A Review. Drug Res. 2015, 65, 287-295. [CrossRef] [PubMed]

299. Nam, K.N.; Park, Y.M.; Jung, H.J.; Lee, J.Y.; Min, B.D.; Park, S.U.; Jung, W.S.; Cho, K.H.; Park, J.H.; Kang, I.; et al. Anti-inflammatory effects of crocin and crocetin in rat brain microglial cells. Eur. J. Pharmacol. 2010, 648, 110-116. [CrossRef] [PubMed]

300. Lv, B.; Huo, F.; Zhu, Z.; Xu, Z.; Dang, X.; Chen, T.; Zhang, T.; Yang, X. Crocin Upregulates CX3CR1 Expression by Suppressing NF-kappaB/YY1 Signaling and Inhibiting Lipopolysaccharide-Induced Microglial Activation. Neurochem. Res. 2016, 41, 1949-1957. [CrossRef]

301. Ishizuka, F.; Shimazawa, M.; Umigai, N.; Ogishima, H.; Nakamura, S.; Tsuruma, K.; Hara, H. Crocetin, a carotenoid derivative, inhibits retinal ischemic damage in mice. Eur. J. Pharmacol. 2013, 703, 1-10. [CrossRef] [PubMed]

302. Yamauchi, M.; Tsuruma, K.; Imai, S.; Nakanishi, T.; Umigai, N.; Shimazawa, M.; Hara, H. Crocetin prevents retinal degeneration induced by oxidative and endoplasmic reticulum stresses via inhibition of caspase activity. Eur. J. Pharmacol. 2011, 650, 110-119. [CrossRef]

303. Nitta, K.; Nishinaka, A.; Hida, Y.; Nakamura, S.; Shimazawa, M.; Hara, H. Oral and ocular administration of crocetin prevents retinal edema in a murine retinal vein occlusion model. Mol. Vis. 2019, 25, 859-868. [PubMed]

304. Ohno, Y.; Nakanishi, T.; Umigai, N.; Tsuruma, K.; Shimazawa, M.; Hara, H. Oral administration of crocetin prevents inner retinal damage induced by N-methyl-D-aspartate in mice. Eur. J. Pharmacol. 2012, 690, 84-89. [CrossRef] [PubMed]

305. Xuan, B.; Zhou, Y.H.; Li, N.; Min, Z.D.; Chiou, G.C. Effects of crocin analogs on ocular blood flow and retinal function. J. Ocul. Pharmacol. Ther. 1999, 15, 143-152. [CrossRef]

306. Qi, Y.; Chen, L.; Zhang, L.; Liu, W.B.; Chen, X.Y.; Yang, X.G. Crocin prevents retinal ischaemia/reperfusion injury-induced apoptosis in retinal ganglion cells through the PI3K/AKT signalling pathway. Exp. Eye Res. 2013, 107, 44-51. [CrossRef]

307. Chen, L.; Qi, Y.; Yang, X. Neuroprotective effects of crocin against oxidative stress induced by ischemia/reperfusion injury in rat retina. Ophthalmic Res. 2015, 54, 157-168. [CrossRef]

308. Fernandez-Albarral, J.A.; Ramirez, A.I.; de Hoz, R.; Lopez-Villarin, N.; Salobrar-Garcia, E.; Lopez-Cuenca, I.; Licastro, E.; Inarejos-Garcia, A.M.; Almodovar, P.; Pinazo-Duran, M.D.; et al. Neuroprotective and Anti-Inflammatory Effects of a Hydrophilic Saffron Extract in a Model of Glaucoma. Int. J. Mol. Sci. 2019, 20, 4110. [CrossRef]

309. Bonyadi, M.H.J.; Yazdani, S.; Saadat, S. The ocular hypotensive effect of saffron extract in primary open angle glaucoma: A pilot study. BMC Complement. Altern. Med. 2014, 14, 1-6. [CrossRef]

310. Li, X.; Song, K.; Yang, J.; Yi, T. Isolation and characterization of 11 new microsatellite loci in Erigeron breviscapus (Asteraceae), an important Chinese traditional herb. Int. J. Mol. Sci. 2011, 12, 7265-7270. [CrossRef] 
311. Li, X.; Peng, L.Y.; Zhang, S.D.; Zhao, Q.S.; Yi, T.S. The relationships between chemical and genetic differentiation and environmental factors across the distribution of Erigeron breviscapus (Asteraceae). PLoS ONE 2013, 8, e74490. [CrossRef] [PubMed]

312. Yiming, L.; Wei, H.; Aihua, L.; Fandian, Z. Neuroprotective effects of breviscapine against apoptosis induced by transient focal cerebral ischaemia in rats. J. Pharm. Pharmacol. 2008, 60, 349-355. [CrossRef]

313. Wang, W.W.; Lu, L.; Bao, T.H.; Zhang, H.M.; Yuan, J.; Miao, W.; Wang, S.F.; Xiao, Z.C. Scutellarin Alleviates Behavioral Deficits in a Mouse Model of Multiple Sclerosis, Possibly through Protecting Neural Stem Cells. J. Mol. Neurosci. 2016, 58, 210-220. [CrossRef]

314. Zhu, Y.; Jiang, Y.; Liu, Z.; Luo, X.; Wu, Z. The affect of Erigeron Breviscapus (Vant.) Hand-Mazz on axoplasmic transport of optic nerve in rats with experimentally elevated intraocular pressure. Zhonghua Yan Ke Za Zhi 2000, 36, 289-291.

315. Jiang, B.; Jiang, Y.Q. The neuroprotective effect of erigeron breviscapus (vant) hand-mazz on retinal ganglion cells after optic nerve crush injury. Zhonghua Yan Ke Za Zhi 2003, 39, 481-484.

316. Lu, X.J.; Zhang, F.W.; Cheng, L.; Liu, A.Q.; Duan, J.G. Effect on multifocal electroretinogram in persistently elevated intraocular pressure by erigeron breviscapus extract. Int. J. Ophthalmol. 2011, 4, 349-352. [CrossRef]

317. Zhu, J.; Chen, L.; Qi, Y.; Feng, J.; Zhu, L.; Bai, Y.; Wu, H. Protective effects of Erigeron breviscapus Hand.-Mazz. (EBHM) extract in retinal neurodegeneration models. Mol. Vis. 2018, 24, 315-325.

318. Zhong, Y.; Xiang, M.; Ye, W.; Cheng, Y.; Jiang, Y. Visual field protective effect of Erigeron breviscapus (vant.) Hand. Mazz. extract on glaucoma with controlled intraocular pressure: A randomized, double-blind, clinical trial. Drugs R D 2010, 10, 75-82. [CrossRef]

Publisher's Note: MDPI stays neutral with regard to jurisdictional claims in published maps and institutional affiliations. 